\title{
WestVirginiaUniversity
}

THE RESEARCH REPOSITORY @ WVU

Graduate Theses, Dissertations, and Problem Reports

2010

\section{Residual feed intake, body composition and fertility in yearling beef heifers}

Kevin S. Shaffer

West Virginia University

Follow this and additional works at: https://researchrepository.wvu.edu/etd

\section{Recommended Citation}

Shaffer, Kevin S., "Residual feed intake, body composition and fertility in yearling beef heifers" (2010). Graduate Theses, Dissertations, and Problem Reports. 2975.

https://researchrepository.wvu.edu/etd/2975

This Thesis is protected by copyright and/or related rights. It has been brought to you by the The Research Repository @ WVU with permission from the rights-holder(s). You are free to use this Thesis in any way that is permitted by the copyright and related rights legislation that applies to your use. For other uses you must obtain permission from the rights-holder(s) directly, unless additional rights are indicated by a Creative Commons license in the record and/ or on the work itself. This Thesis has been accepted for inclusion in WVU Graduate Theses, Dissertations, and Problem Reports collection by an authorized administrator of The Research Repository @ WVU. For more information, please contact researchrepository@mail.wvu.edu. 


\title{
Residual Feed Intake, Body Composition and Fertility in Yearling Beef Heifers
}

\author{
Kevin S. Shaffer \\ Thesis submitted to the \\ Davis College of Agriculture, Natural Resources and Design \\ at West Virginia University \\ in partial fulfillment of the requirements \\ for the degree of
}

\section{Master of Science}

in

\section{Animal and Nutritional Sciences}

\author{
Eugene E. D. Felton, Ph.D., Chair \\ E. Keith Inskeep, Ph.D. \\ John E. Warren, Ph.D. \\ Wayne R. Wagner, Ph.D. \\ Department of Animal and Nutritional Sciences
}

Morgantown, West Virginia
2010

Keywords: Residual Feed Intake, Feed Efficiency, Beef Heifers, Puberty 


\title{
ABSTRACT
}

\section{Residual Feed Intake, Body Composition and Fertility in Yearling Beef Heifers}

\author{
Kevin S. Shaffer
}

One hundred thirty-seven spring born yearling beef heifers of English breed types were used to determine the relationships between residual feed intake (RFI) and growth rate, body composition, mature size, and fertility. Heifers were housed in a drylot facility during the trial and data were collected over a two-year period (year $1, n=67$; year 2, $\mathrm{n}=70$ ). Individual feed intake, body weight (BW), body condition score (BCS), hip height (HH), and carcass ultrasound measurements (subcutaneous rib and rump fat; RIF and RUF, respectively, longissimus muscle area; LMA, and intramuscular fat; IMF) were collected. Individual feed intakes were expressed as kg of TDN consumed per day and were used to calculate RFI combining both years' data. Heifers averaged $387.0 \pm$ 19.4 days of age (DOA) and $337.1 \pm 29.9 \mathrm{~kg} \mathrm{BW}$ at trial initiation. Mean average daily gain (ADG) was $1.14 \pm 0.21 \mathrm{~kg} / \mathrm{d}$. A slight relationship $(\mathrm{P}<0.05)$ existed between RFI and both RIF and RUF ( $\mathrm{r}=0.19$ and 0.17 , respectively) initially and was increased ( $\mathrm{r}=$ 0.27 and $r=0.24$, respectively; $\mathrm{P}<0.01$ ) at trial conclusion. Heifers were classified into groups (POS; mean RFI= 0.74 vs. NEG; -0.73 and HIGH; mean RFI= 1.06, MEDIUM;

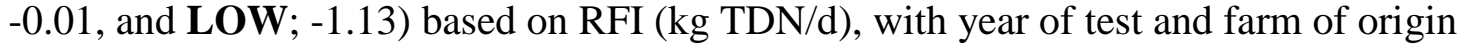
included in the model as covariates. POS heifers tended to possess more RIF $(\mathrm{P}=0.051)$

and ribeye area $\left(\mathrm{cm}^{2}\right)$ per hundred $\mathrm{kg}$ of BW (LMACWT) $(\mathrm{P}=0.078)$ than NEG heifers at trial initiation, while LMACWT was greater in POS heifers at trial conclusion $(\mathrm{P}<$ 0.01). POSITIVE heifers reached puberty earlier than NEG heifers (414 vs. 427 day, respectively, $\mathrm{P}=0.03)$. MEDIUM heifers exhibited less RIF and RUF $(\mathrm{P}<0.05)$ when compared to either HIGH or LOW at trial initiation. LMACWT was less $(\mathrm{P}<0.05)$ in LOW RFI heifers when compared to HIGH but did not differ $(P>0.10)$ from MEDIUM females at both beginning and end of test. A negative linear relationship existed between RFI and AGE at PUBERTY (P < 0.05). Each one unit increase in RFI corresponded to a reduction of 7.54 days in AGE at PUBERTY; however, no differences existed between groups in pregnancy or conception rate. Given that RFI was significantly correlated with subcutaneous fat measures and the known relationship between fatness and reproductive maturity, further investigation is warranted. 


\section{ACKNOWLEDGEMENTS}

I would like to take this opportunity to extend a special thanks to Dr. Felton for the opportunities he has provided me during my graduate career. Doc has generously allowed me to take my own path in pursuing my education and for that I am truly grateful. I feel I would be hard-pressed to find a program elsewhere that would have given me the liberty in personalizing my program to my interests and goals as I have found here. The knowledge, education, and support Dr. Felton has provided are invaluable.

I would also like to thank my committee members, Drs. Inskeep, Warren, and Wagner for their guidance throughout my program. A special thank you goes to Dr. Wagner for the countless hours spent discussing cattle. Your wealth of knowledge and unique perspective about the beef industry has greatly enhanced my learning experience and inspired me to continue my education.

I would be remiss if I did not extend thanks to my fellow graduate students, Jason Smith, Julie Mankey, and Matt Dean, who not only contributed greatly to completion of my program but whom I also count as friends. Jason deserves a heartfelt thank you for the invaluable assistance he provided as well as for the "enhancement” our office

environment. Several undergraduate assistants also deserve thanks for their assistance in data collection and laboratory work, especially Mr. Vinson Snuffer.

During my program, I had the special opportunity to spend time at the Wardensville experiment station. I would like to take this opportunity to extend a special thank you to Mr. Jerry Yates, Mr. Bill Ferrell, and Mr. Steve Rudolph as well as the 
entire Reymann Memorial Farm crew for their generosity, unwavering dedication, and willingness to help at all times. My graduate experience, to say the least, would not have been the same without each of you. I am honored to have gotten to know you and count you all as friends.

Lastly, I would like to thank my family for the love and support they have provided me in all my endeavors. My parents have always instilled in me the belief that I could do anything, and for that, I am truly grateful. As well, I want to especially thank my wife, Monica, for her patience, love, and support as I continue my education and pursue my dreams. 


\section{TABLE OF CONTENTS}

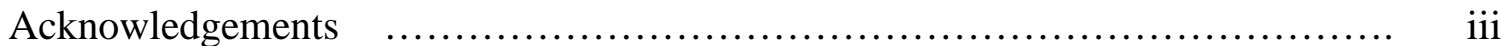

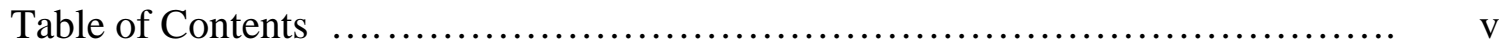

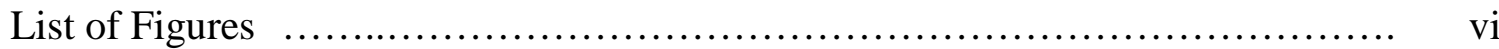

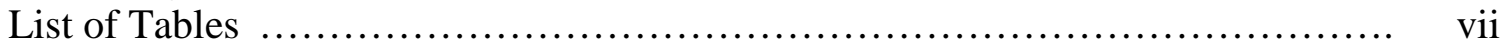

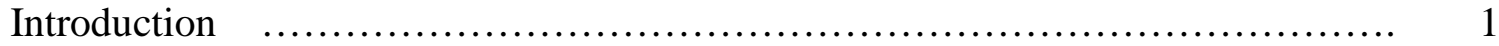

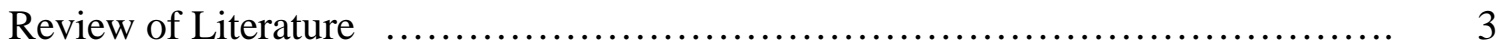

I. Feed Efficiency-A Bioenergetics Perspective .................... 3

II. Factors Affecting Maintenance Requirements .................... 4

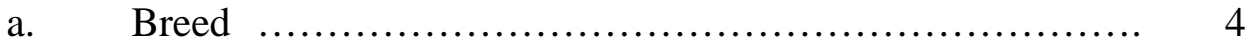

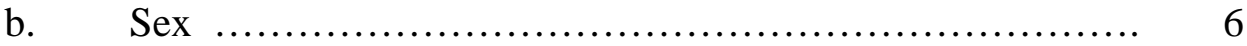

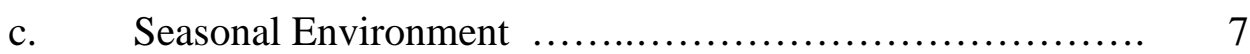

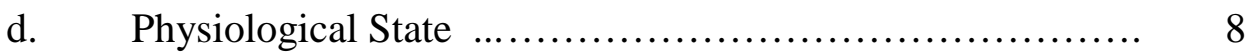

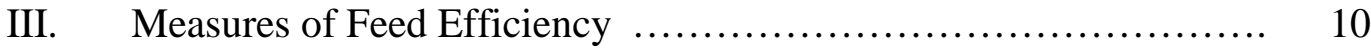

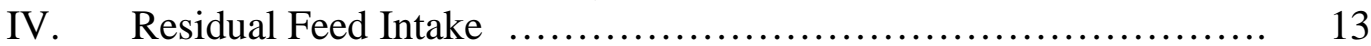

a. $\quad$ Test Duration and Validation ............................ 13

b. Phenotypic RFI and Production Trait Relationships ......... 14

c. Physiological Mechanisms_-A Potential Explanation ...... 20

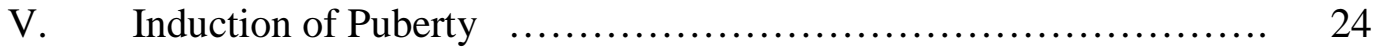

a. Genetics ............................................... 25

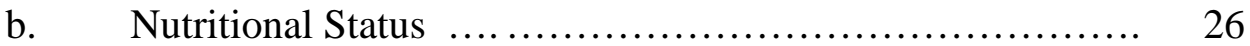

c. Season, Environment and Other Factors .................. 27

d. Hormonal Regulation ................................... 28

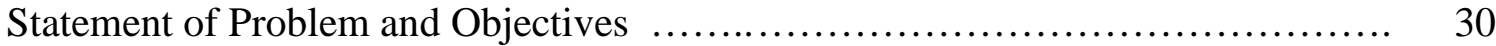

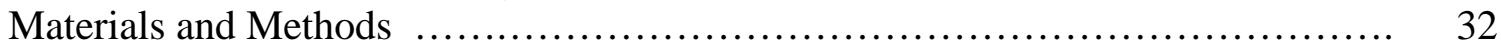

Results ................................................................... 40

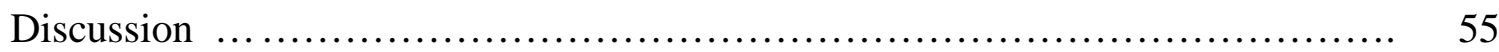

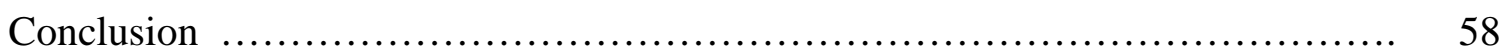

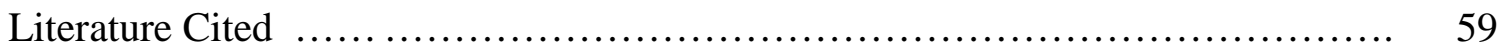

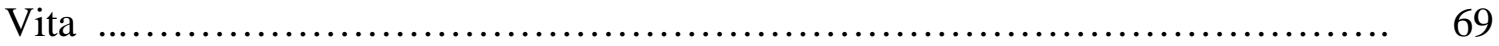

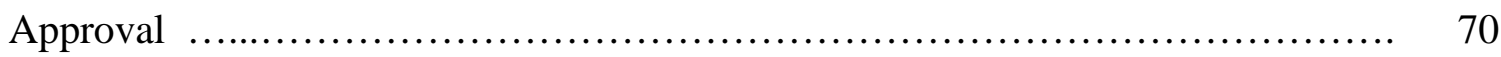




\section{LIST OF FIGURES}

Figure

Page

1. Contributions of biological mechanisms to variation in residual feed intake as determined from experiments on divergently selected cattle. Adapted from Richardson and Herd (2004)

2. Schematic illustration of the hypothalamic-pituitary-ovarian axis showing neuronal and endocrine inputs that control the release of luteinizing hormone and follicle stimulating hormone. From Schillo et al. (1992). ................

3. Summary of important endocrine events associated with onset of puberty in the heifer. Patterns of LH, estradiol, and progesterone are represented by the solid, dashed, and dotted lines, respectively. The shaded area represents degree of responsiveness of the hypothalamic-pituitary axis to estradiol negative feedback. From Schillo et al. (1992).

4. Outline of experimental procedures.

5. Fitted regression lines for Year-by-Farm combination. 


\section{LIST OF TABLES}

Table

Page

1. Composition and Nutrient Analysis of Diets. ........................ 35

2. Heifer descriptive statistics pooled across years. ...................... 41

3. Descriptive statistics for POSITIVE vs. NEGATIVE RFI heifers. .......... 42

4. Descriptive statistics for HIGH, MEDIUM and LOW RFI heifers. ......... 43

5. BCS and carcass ultrasound traits of POSITIVE and NEGATIVE heifers at trial initiation and conclusion.

6. BCS and carcass ultrasound traits of HIGH, MEDIUM and LOW heifers at trial initiation.

7. BCS and carcass ultrasound traits of HIGH, MEDIUM and LOW heifers at trial conclusion.

8. Change in (final - initial) carcass ultrasound traits of POSITIVE and NEGATIVE RFI heifers.

9. Change in (final - initial) carcass ultrasound traits of HIGH, MEDIUM and LOW heifers.

10. Phenotypic correlations of RFI with measures of performance, intake, and mature size.

11. Phenotypic correlations of RFI with initial measures of body composition... 50

12. Phenotypic correlations of RFI with final measures of body composition.....

13. Phenotypic correlations of RFI with change in (final - initial) body composition.

14. Summary statistics for AP.

15. Type 3 tests of fixed effects. 


\section{INTRODUCTION}

In recent years the beef industry and agriculture as a whole have faced exceedingly greater economic challenges due to a global economic downturn, biosecurity issues, and the search for alternative energy. Copious amounts of high energy feedstuffs formerly utilized predominantly for livestock feed have been required for alternative fuel production. Ultimately, these factors have led to an increase of over $\$ 43.5$ billion dollars in the annual cost of livestock production since 2003 (USDA-NASS, 2009). As a result, the beef industry has looked for various ways to increase profitability and/or reduce input costs.

Traditionally, beef producers have increased profitability by increasing production; however, the current circumstances have directed the focus toward reducing input costs. Approximately $70 \%$ of the total cost of beef production is directly related to feed costs. It has been shown that the nation’s 32.2 million breeding females (USDANASS, 2009) utilize an estimated 65\% of the energy required for production (Gregory, 1972), and 70 to $75 \%$ of total metabolizable energy requirements are consumed solely for maintenance functions (Ferrell and Jenkins, 1985a). Ultimately, around one-half of the total cost of production is directly related to maintenance requirements of breeding females.

In order to maximize profitability, it is logical to attempt to maximize production efficiency, or the ratio of inputs to outputs. Feed utilization efficiency has typically been quantified in this manner; however, selection for improvement in the ratio of feed:gain has led to an increase in mature size and feed intake of breeding females (Herd and 
Bishop, 2000). An increase in mature size may delay the onset of puberty, resulting in a subsequent reduction in the lifetime productivity of replacement females (Lesmeister et al., 1973). Ultimately, these factors reduce income, increase input costs, and lead to a net reduction in profit.

Fortunately, there are currently other measures of feed utilization efficiency in beef cattle. The concept of residual feed intake (RFI) was introduced by Koch et al. (1963) and by design is independent of mature size and performance. Koots and Gibson (1998) determined feed efficiency expressed as RFI to be one of the most economically important traits in beef production; however, only recent advancements in technology have allowed for the widespread collection of data necessary for the calculation of RFI. As a result, there has been limited investigation into the generation of RFI data, the relationship of RFI and production traits as well as long term physiological effects and effects on profitability. Thus, the focus of this literature review will be on the factors affecting feed efficiency in beef cattle, RFI and the potential of selection for improvement in RFI and feed efficiency, and a short section reviewing the induction of puberty in females. 


\section{LITERATURE REVIEW}

\section{FEED EFFICIENCY—A BIOENERGETICS PERSPECTIVE}

In order to effectively comprehend feed utilization efficiency, it is first necessary to develop an understanding of energetic relationships with physiological requirements for feedstuffs. It is well established that all physiological processes utilize energy generated from the breaking of high-energy phosphate bonds. These bonds are generated through the transformation of dietary energy. Historically, dietary energy values were hard to quantify in terms of energy utilized by the animal. The California Net Energy System, proposed by Lofgreen and Garrett (1968), describes how dietary gross energy is broken down into subcomponents of energy loss and retained energy as determined by comparative slaughter methods. More specifically, the system separates dietary energy into two components: energy utilized for maintenance functions $\left(\mathrm{NE}_{\mathrm{m}}\right)$ from which there is no net change in whole body energy, and retained energy, or energy utilized for productive functions above maintenance $\left(\mathrm{NE}_{\mathrm{g}}\right)$, from which there is a net gain in whole body energy. This system more accurately quantifies the energy content of forages when compared to concentrates, specifically under maintenance feeding conditions. Today, the system is widely accepted and commonly used in the evaluation of feedstuffs.

Maintenance requirements comprise the majority of energetic requirements of beef cattle. Ferrell and Jenkins (1987) reported that approximately $70 \%$ of the metabolizable energy requirement of mature beef cows was used solely for maintenance functions. In mature bulls this figure rose to greater than 90\%. Even growing cattle at maximum intake will rarely use less than $40 \%$ of dietary metabolizable energy for 
maintenance functions (NRC, 1996). It is important to note that maintenance energy is used with greater efficiency than energy utilized for physiological functions above maintenance, i.e. growth or lactation (NRC, 1996).

Variation in maintenance requirements is the result of several factors and subsequent interactions between those factors. Genotype, environment, and physiological state all contribute to individual requirements for maintenance. These same factors have major effects on the efficiency of feed utilization.

\section{FACTORS AFFECTING MAINTENANCE REQUIREMENTS}

In light of the material present in the literature and the focus of this literature review, I feel that it would be unwise to describe the influences responsible for variation in feed efficiency relative to FCR as they are most often described. Although very little information is available describing those factors relative to RFI, it is necessary to examine those items responsible for variation in individual feed requirements. Greater than $40 \%$ of feed requirements during all stages of beef production are utilized for maintenance functions, so the factors influencing maintenance requirements of beef cattle were investigated. These factors are discussed in the following sections.

\section{Breed}

As early as 1911, Armsby and Fries noted that "scrub" steers were less energetically efficient than "good” beef animals. More recently, Klosterman et al. (1968) and Turner et al. (1974) reported that maintenance requirements of Hereford and 
Charolais cows are independent of breed and generally related to body size. Both studies indicated that body condition contributed significantly to differences in maintenance requirements. In a study with cows in both late gestation and early lactation, Lemenager et al. (1980) determined that weight alone cannot accurately predict energy requirements of cows, particularly in larger animals and those with varying levels of milk production. Ferrell and Jenkins (1983) predicted, based on extended feeding trials, that Simmental and Charolais cross cows required more dry matter for maintenance than Angus-Hereford and Jersey cross cows. Similarly, Laurenz et al. (1991) reported that mature nonlactating, nonpregnant Simmental cows required 16.1\% more metabolizable energy (ME) for weight maintenance than Angus cows while Old and Garrett (1987) found no difference in maintenance requirements of Hereford and Charolais steers.

In a study using five breeds and their reciprocal breed crosses, metabolizable energy requirements for energy and weight stasis indicated that Angus, Brahman and Hereford cows had similar maintenance requirements (91.6, 93.8, and $95.3 \mathrm{kcal} / \mathrm{BW}^{0.75}$, respectively), while Holsteins were significantly higher $\left(115.7 \mathrm{kcal} / \mathrm{BW}^{0.75}\right)$ with Jersey cows $\left(140.4 \mathrm{kcal} / \mathrm{BW}^{0.75}\right.$ ) having the largest requirements for maintenance (Solis et al., 1988). Ferrell and Jenkins (1984) reported that the ME to maintain energy equilibrium was greater in Simmental and Jersey cross cows (160 and $145 \mathrm{kcal} / \mathrm{BW}^{0.75}$, respectively) than Angus-Hereford and Charolais cross cows (130 and $129 \mathrm{kcal} / \mathrm{BW}^{0.75}$, respectively), indicating that cows with higher milk production potential have greater maintenance requirements. Similar results have been observed by Blaxter and Wainman (1966), Garrett (1971), Ferrell and Jenkins (1984) and Montano-Bermudez et al. (1990) for breeds with higher milk production potential. Similar to the report by Old and Garrett, 
Gaskins et al. (1982) observed no difference in the maintenance requirements when comparing Jersey-Angus and Simmental-Angus cross bulls.

Ultimately, both growing and mature Bos indicus cattle require about 10 percent less maintenance energy than Bos taurus breeds, and of the Bos taurus breeds, dairy or dual-purpose breeds require about 20 percent more maintenance energy than beef breeds (NRC, 1996). Additionally, most reports available in the literature document breed differences in maintenance requirements; however, direct comparison of the data is difficult due to variation in methodology and breeds compared. Nonetheless, it is generally apparent that maintenance requirements vary considerably with genetic source.

\section{Sex}

In a report by Ferrell (1979) using comparative slaughter methods, intact ram lambs exhibited a greater daily requirement for ME than ewe lambs (112 vs. 109 kcal/BW ${ }^{0.75}$, respectively). A similar but significantly larger difference (16.5\%) in ME required for maintenance was observed by Ferrell and Jenkins (1985b) when comparing intact Simmental bulls and heifers; however, in the same study, Hereford bulls and heifers only differed by 2 percent. When requirements were pooled across breeds, bulls required around 12 percent more ME for weight stasis than females (123 vs 110 $\mathrm{kcal} / / \mathrm{BW}^{0.75}$ ). When comparing females to castrate males, the NRC (1996) concluded, based predominantly on extensive comparative slaughter experiments by Garrett, maintenance requirements to be similar. However, this conclusion was not supported by Hotovy et al. (1991) in that heifers had significantly lower maintenance requirements than steers although both steers and heifers utilized ME for maintenance with similar efficiency. This discrepancy may be due in part to the small sample size $(\mathrm{N}=24)$ in the 
study by Hotovy et al. (1991) and the fact that the heifers were in mid-gestation.

Furthermore, a comparison of steers with intact bulls indicated that intact males exhibit maintenance requirements greater than those of castrate males (NRC, 1996). All together, the available data indicate that intact males have maintenance requirements approximately 12 to 15 percent higher than genetically similar steers or heifers during the post-weaning growth and development period.

\section{Seasonal Environment}

As open systems, all ruminant livestock exchange air, energy, water and carbon with their environment. In doing so, environmental conditions impact the physiological state as the body attempts to maintain homeostasis, part of which is the regulation of body temperature. Ruminants and all warm-blooded animals have a thermoneutral zone, or an ambient temperature range in which no net energy is expended in the maintenance of body temperature. In a thermoneutral environment, heat production is a function of feed intake and efficiency (NRC, 1996). When the effective ambient temperature moves outside the thermoneutral zone, energy must be expended either in the generation or dissipation of heat. In both cases, metabolic rate increases and is followed by a concurrent increase in maintenance requirements. As a result, seasonal and environmental effects as a whole were thought to be predominantly related to temperature, although season may independently affect maintenance requirements (NRC, 1996).

In a study using mature, nonpregnant, nonlactating Angus and Simmental cows, Laurenz et al. (1991) reported that maintenance requirements for weight stasis were lowest in fall and winter while requirements were highest in summer, which may indicate 
a greater effect by heat rather than cold stress. When expressed as maintenance requirements for energy stasis, a comparable pattern was observed for Angus cows but not for Simmental cows. Christopherson et al. (1979) reported similar results in cattle and bison at $0^{\circ} \mathrm{C}$; however, maintenance requirements of cattle were greatly increased in both winter and summer when temperature was maintained at $-30^{\circ} \mathrm{C}$ and $10^{\circ} \mathrm{C}$, respectively. Blaxter and Boyne (1982) further showed minimal maintenance requirements in sheep during winter and maximal requirements during summer. It appears that season has an effect upon maintenance energy expenditures of ruminants; however, the literature regarding seasonal differences independent of temperature is limited. More reports like that of Christopherson et al. will be necessary to totally elucidate the impact of season upon maintenance requirements, as the available literature would indicate this effect is not wholly independent of temperature.

\section{Physiological State}

Generally, variations in physiological state are due to the processes of reproduction and are specific to females as "growth and development of the fetus is energetically very costly” (Moe and Tyrell, 1972). As well, post parturient milk production can have large effects on energy requirements, an effect that is dependent on milk production potential (Montano-Bermudez et al., 1990).

Brody (1945) noted that total heat production increases during gestation. Graham (1964) and Rattray et al. (1974) using indirect calorimetry and comparative slaughter methods, respectively, observed a similar phenomenon in sheep. Additionally, Graham (1964) observed that ME intake/ kg fetus accounted for approximately 10 percent of ewe maintenance requirements and daily fetal energy requirements accounted for 70 percent 
of blood glucogenic substances at term. In a summary of several experiments with Holstein cows, Moe and Tyrell (1972) concluded that ME required at term was 75 percent greater for gestating cows than nonpregnant cows of similar body weight. While these experiments provide indirect evidence of differences in maintenance requirements between gestating and nonpregnant cattle and sheep, Ferrell et al. (1976) saw no difference in maintenance requirements of Hereford heifers when using comparative slaughter methods, even though fasting heat production increased throughout gestation. Ultimately, increased heat production during pregnancy is "assumed to be attributed to the productive process of pregnancy" (NRC, 1996). In combination with the additive nutritional requirements of the fetus, hormonal maintenance of pregnancy may account for a portion of the increase in heat production during gestation. Rumsey et al. (1980) reported a 4 percent increase in daily heat production per unit of metabolic body weight in steers implanted with progesterone and estrogen, while net energy required for gain was reduced by 19 percent in a similar study (Hutcheson et al., 1997).

With respect to lactation, the literature is somewhat more definitive. Neville and McCullough (1969) determined maintenance requirements of lactating and nonlactating Hereford cows to be 178.4 and $137.4 \mathrm{kcal} \mathrm{ME} / \mathrm{BW}^{0.75}$, respectively, a difference of 31 percent. In a similar experiment, Neville (1974) concluded that lactating cows required 38-41 percent more ME for maintenance than nonlactating cows. Also in agreement with these findings are the results of Patle and Mudgal (1977), who noted a difference of 32.9 percent between lactating and nonlactating cows. Additionally, Patle and Mudgal (1977) stated that requirements vary only slightly among stages of lactation. Citing sources of unpublished data, the NRC (1996) concluded maintenance requirements of lactating cows 
to be about 20 percent higher than nonlactating cows. However, based upon the literature, the NRC conclusion is somewhat conservative and maintenance requirements of lactating cows are actually in the range of 30 percent greater than nonlactating cows. The discrepancy between lactating and nonlactating cows may be due to the proliferation and activity of mammary tissue during lactation as well as the nutrients required for synthesis of milk solids. However, one could argue that lactation and reproduction are not truly maintenance functions as they are not essential for support of the life of the cow.

\section{MEASURES OF FEED EFFICIENCY}

As defined by Webster's (1997), efficiency is the ratio of effective work to the energy expended in producing it or simply output divided by input. With respect to beef cattle, the efficiency of feed and/or feed energy utilization has been expressed similarly in an attempt to provide a useful selection criterion for the improvement of efficiency. Quantifying the efficiency of feed use for selection, however, is an attempt to enumerate individual metabolic differences, and yet, metabolism itself is not wholly understood.

Kellner (1909) first described the efficiency of feed use as the partial efficiency of growth (PEG), or the energetic efficiency of weight gain; however, the most common measure of feed efficiency in beef cattle is feed conversion ratio (FCR), which is the ratio of feed consumed per pound of body weight gain (Brody, 1945). Feed conversion ratio is easily calculated and does not require sophisticated facilities or equipment. Conversely, FCR does not account for differences in maintenance requirements and is influenced by differences in growth and maturity patterns (Archer et al., 1999). Selection 
for FCR can result in increased growth rate and size of mature females (Archer et al., 1999; Herd and Bishop, 2000). As a result, other measures have been proposed.

While investigating energy metabolism, Klieber (1947) described feed efficiency as daily weight gain per unit of metabolic body weight $\left(\mathrm{BW}^{0.75}\right)$, or Klieber ratio (KR). Fitzhugh and Taylor (1971) measured efficiency as weight gain as it relates to instantaneous body size, or relative growth rate (RGR). By quantifying efficiency in this manner, both maintenance requirements and growth needs are accounted for. Taking a similar approach, Koch et al. (1963) proposed regressing metabolic body weight and average daily gain against individual animal daily feed intake. Known as residual feed intake, or RFI, this measure of efficiency predicts individual feed intake and quantifies efficiency as the residual between the actual and predicted value. Genetic variation in RFI has been noted (Koch et al., 1963; Liu et al., 2000; Herd and Bishop, 2000; Arthur et al., 2001b; Nkrumah et al., 2007c, Hoque et al., 2010) in both growing cattle and cattle at maintenance (Archer et al., 1999). As well, RFI has been shown to be independent of mature size and growth rate (Crews, 2005).

The aforementioned measures of efficiency have distinct approaches to measurement; however, direct comparison of the validity of these measures as selection criteria has only recently been investigated. In a study compiling data on over 700 Charolais bulls in a post-weaning performance test, Arthur et al. (2001a) observed that RFI was phenotypically independent of its component traits, but positively correlated with feed intake $\left(r^{2}=0.60\right)$. Strong positive correlations existed between ADG and both KR and RGR while negative correlations existed between ADG and both FCR (-0.54) and PEG (-0.14). Correlations with BW and KR, RGR, PEG and FCR were all 
significant but near zero. Arthur et al. (2001a) also found that RFI was moderately to highly heritable $\left(h^{2}=0.39 \pm 0.04\right)$ and highly correlated $(r=0.85)$ over two separate test periods. Similar results were obtained by Nkrumah et al. (2004) in a study utilizing hybrid steers and bulls during the same physiological time period. In this study, RFI, PEG, and FCR indicated that steers were less efficient than bulls whereas RGR and KR did not. The inability of RGR and KR to detect sex differences in efficiency suggests that these measures may be incapable of detecting true differences in energetic efficiency. In the same study, PEG was correlated positively with ADG (0.24) whereas it was slightly negative, yet significantly correlated with ADG (-0.14) in the study by Arthur et al. (2001a). As a result, Nkrumah et al. (2004) suggested that RFI is the only measure of efficiency phenotypically independent of its component traits and unaffected by pretest environment. Most recently, Hoque et al. (2009) compared FCR, PEG, RGR, KR, and RFI utilizing over 22,000 progeny records of Japanese Black cattle. Although genetic parameters were estimated for the traits listed, RFI was preferred over other measures of efficiency. Conversely, a feedlot finishing study Cruz et al. (2010) noted that RFI accounted for only 18 percent of the variation in the cost of gain where ADG and DMI accounted for 98.5 percent, leading them to suggest that RFI is less useful then FCR as an indicator of feedlot efficiency and profitability. Even so, research has shown selection for RFI should be independent of mature size and performance, making it the most viable measure of feed efficiency investigated thus far. 


\section{RESIDUAL FEED INTAKE}

In 1963, Koch et al. introduced the concept of net feed efficiency or RFI, an index of energetic efficiency combining estimates of both maintenance and growth requirements in the prediction of individual animal feed intake. The calculated or expected feed intake is compared to actual intake and efficiency is measured as the residual; however, only recent advances in technology and computing have allowed for the simultaneous, automated measurement of individual animal feed intake. Thus, the information available in the literature on RFI in beef cattle is fairly limited but is reviewed in the following sections.

\section{Test Duration and Validation}

A minimum performance test of 70 days with BW recorded biweekly and a minimum 35 days of individual feed intake data over that same time period are sufficient for the calculation of ADG, FCR, and RFI (Archer et al., 1997). In a similar study utilizing multiple biological types of cattle, Archer and Bergh (2000) recommended a 7084 day test to accurately calculate RFI. Using break point analysis techniques, Wang et al. (2005) determined optimum test duration to be 82.6 and 69.5 days for British and Continental bulls, respectively. In a later test using hybrid steers with weekly BW records and an automated feeding system, Wang et al. (2006) determined optimum test length to be 63, 35, 42 and 63 days for ADG, DMI, FCR and RFI, respectively. An evaluation of test duration over two forage types and three levels of concentrate inclusion yielded a similar 63-day test duration with a 100 percent alfalfa silage diet; however, when the diet consisted of 15 percent barley grain, minimum test duration reached 84 
days indicating test duration may be dependent upon test diet (Goonewardene et al., 2004). However, a dietary effect is unlikely as the reports by Archer et al. (1997), Archer and Bergh (2000), Wang et al. (2005), and Wang et al. (2006) were generated using a variety of feedstuffs, ration types and levels of concentrate. Diets fed were pelleted or total mixed rations and contained from 20 to 80 percent concentrate. As well, the data were collected in a variety of environmental conditions, both geographically and seasonally and across several breeds and breed types.

From the literature cited above, it is apparent that shortening test duration for RFI is limited by an accurate assessment of weight gain. As a result, Kearney et al. (2004) utilized an automated swine feeding system modified for cattle and equipped to record BW automatically to evaluate test duration for weight gain. However, the significant increase in the number of BW records reduced test duration for the calculation of RFI to only 56 days. A slight increase in acceptable error could further reduce test duration to 48 days, but may not be advantageous for research and genetic evaluation purposes. A 70day test for the calculation of RFI is recommended.

\section{Phenotypic RFI and Production Trait Relationships}

Selection for lower residual energy intake was associated with increased carcass fatness (Jensen et al., 1992). In contrast, Cruz et al. (2010) observed no difference in carcass fat or lean when comparing low and high RFI steers during a finishing trial. Similarly, Castro Bulle et al. (2007) observed that low vs. high RFI Angus x Hereford steers did not differ in measures of carcass fatness, but reported that low RFI steers tended to gain less fat than high RFI steers (494 vs 719 g/d). Mader et al. (2009) also reported that RFI was not related to BW, hot carcass weight, back fat, or longissimus 
muscle area (LMA), but was related to trim and kidney fat $(\mathrm{r}=0.34)$. Several reports have nonetheless indicated that high or positive RFI is related to increased fatness.

Arthur et al. (2001b) reported that RFI was correlated positively ( $r=0.14$ ) with ultrasound back fat (UBF) in both bulls and heifers that had been selected divergently for post-weaning RFI. In a very intensive study using hybrid steers at various slaughter points, Basarab et al. (2003) found RFI to be positively correlated $(r=0.15)$ to end of test UBF. A slightly stronger correlation $(r=0.22)$ was observed between RFI and gain in UBF during the test period. Basarab et al. (2003) further evaluated differences in body composition by dividing steers into low ( $<0.5$ SD below mean), medium $( \pm 0.5 \mathrm{SD})$, and high ( $>0.5$ SD above mean) RFI groups. Low RFI steers gained significantly less whole body fat and more whole body water than both medium and high RFI steers; however, there were no differences in ADG, BW, or hip height. These findings are in agreement with Schenkel et al. (2004), who reported a phenotypic correlation of 0.17 between RFI and UBF. Recent Australian research has determined that low RFI animals possess less subcutaneous fat (Channon et al., 2004) and that there is a high genetic correlation ( $\mathrm{r}=$ 0.48 to 0.79 ) between RFI and subcutaneous fat measures (Robinson and Oddy, 2004). A three year finishing and slaughter study by Nkrumah et al. (2007c) resulted in a slightly stronger phenotypic correlation $(r=0.25)$ between RFI and UBF than previously reported, although RFI was independent of BW and lean mass. Nkrumah et al. (2007c) separated steers into low, medium, and high RFI groups and found that low RFI steers gained less UBF than either medium or high RFI groups. End of test UBF was greater for high RFI steers than medium and low steers. Interestingly, there were no differences in final live weight, slaughter weight, or carcass weight based on RFI classification. 
In four trials with Angus bulls, RFI was not related to ADG or BW, but was related positively to UBF $(r=0.20)$, gain in $\operatorname{UBF}(r=0.30)$, and LMA $(r=0.17)$ (Lancaster et al., 2009a). Lancaster et al. (2009a) also classified bulls as either low, medium, or high RFI; high RFI bulls possessed more UBF than low RFI bulls but were not different from medium bulls. Low RFI bulls gained less UBF than both medium and high RFI bulls and possessed less LMA than high RFI bulls $\left(18.99 \mathrm{~cm}^{2}\right.$ vs $22.04 \mathrm{~cm}^{2}$ for low and high, respectively). In a similar study with Brangus heifers, Lancaster et al. (2009b) reported no relationship between RFI and ADG or BW. RFI was, however, positively and more strongly correlated with end of test UBF $(r=0.36)$, gain in UBF $(r=$ 0.22), and gain in LMA $(r=0.55)$ than in previous reports. The reason for the strengthening of this relationship is unclear, but may potentially be related to sex differences in whole body metabolism and maintenance. However, Arthur et al. (2001b) reported a much lower estimate of the relationship when using bulls and heifers. Other reports utilizing growing heifers are limited but generally agree that low and medium RFI heifers gained less UBF (Lancaster et al., 2009b) and/or possessed less UBF at end of test (Kelly et al., 2010). Likewise, no differences in performance or mature size have been reported.

It is evident that a relationship exists between RFI and body composition in young growing cattle with high RFI animals exhibiting greater body fat, particularly subcutaneous fat. As a result, it may be necessary to include measures of body composition in the model for calculating RFI; however, differences in lean tissue mass are variable and less well defined. Several researchers have included measures of fatness (UBF, gain in UBF, and marbling score) and in some cases lean (LMA) in the model for 
the calculation of RFI (Richardson et al., 2001; Basarab et al., 2003; Schenkel et al., 2004; Nkrumah et al., 2007c; Lancaster et al., 2009a; Lancaster et al., 2009b; Kelly et al., 2010). In all cases, the fit of the model was improved and relationships with carcass composition, both phenotypically and genetically, were removed. In the case of Basarab et al. (2003), UBF and marbling score accounted for 6.8 percent of the variation in DMI. The addition of carcass measures, particularly gain in UBF, should make RFI a more robust selection index for feed efficiency.

Other production traits such as ADG, BW, hip height, and scrotal circumference are not related to RFI (Arthur et al., 2001b; Basarab et al., 2003; Schenkel et al., 2004; Kelly et al., 2010). Even though RFI is independent of most phenotypic traits, very few researchers have investigated the potential relationships between RFI and other economically important traits in mature animals. Overall production system efficiency has been investigated in two separate trials with an emphasis on reproductive efficiency, one of the most important traits for determining profitability (Koots and Gibson, 1998), and data are available that indicate low RFI cows may have a 15 percent advantage ( $\mathrm{P}=$ 0.07) in production system efficiency (Herd et al., 1998).

Arthur et al. (2005) studied three production cycles of Angus cows divergently selected for post-weaning RFI. The cows were the result of 1.5 generations of selection for RFI and differed in estimated breeding value for RFI by $0.8 \mathrm{~kg} / \mathrm{day}$. Cows were grazed year round and were artificially inseminated on two occasions prior to being exposed to clean-up bulls. Low RFI cows were numerically heavier and leaner throughout the experimental period, although they possessed significantly less UBF than high RFI cows at the beginning of each mating season. No differences were observed in 
pregnancy rate (90.5 vs $90.2 \%$ ), calving rate (89.3 vs $88.3 \%$ ), or weaning rate (81.5 vs 80.2\%) between low and high RFI cows, respectively. Additionally, there was no difference in milk yield (7.5 vs $7.8 \mathrm{~kg} / \mathrm{d}$ ), calf birth weight (33.6 vs $31.8 \mathrm{~kg}$ ), or calf weaning weight (191.3 vs $198.4 \mathrm{~kg})$. There was, however, a tendency ( $\mathrm{P}=0.07)$ for low RFI cows to calve later (approx. 5 days) in the calving season than high RFI cows. This was further exemplified by the fact that 22 percent of calves from low RFI cows were by clean-up bulls, whereas only 13 percent of calves from high RFI cows were by clean-up sires. Although not significant, these data indicate that low RFI cows may potentially reach puberty later, since a portion of the females in this study were first calf heifers, or that low RFI cows may potentially have a greater post-partum interval than high RFI cows (Arthur et al., 2005).

Basarab et al. (2007) investigated production system efficiency by separating cows into low, medium, and high RFI groups based upon progeny RFI. Crossbred cows and calves were used, and all matings occurred by natural service. A subset of cows was evaluated for RFI during the second trimester of gestation in each of three years, and all calves, minus those used as replacement females, entered a finishing program during which carcass data were collected. Similar to the report by Arthur et al. (2005), no differences in pregnancy rate $(\mathrm{P}=0.90)$, calving rate $(\mathrm{P}=0.62)$, or weaning rate $(\mathrm{P}=$ 0.79) were observed, although high RFI cows had a higher twinning rate $(\mathrm{P}>0.001)$ than medium or low RFI cows. A subsequent tendency for an increase in calf death loss and calving difficulty $(\mathrm{P}=0.10)$ of high RFI cows was observed. No differences were noted in cow BW throughout the production cycle even though, contrary to Arthur et al. (2005), low RFI cows exhibited 2-3mm more UBF than high RFI cows at all measurement 
periods. This may indicate that the lower maintenance requirements of low RFI animals (Nkrumah et al., 2006) results in the accumulation of body fat as the cow ages (Basarab et al., 2007). Cow RFI and progeny RFI measured in the same year were related $(\mathrm{r}=$ 0.30), however, the level of this relationship was fairly low, indicating that cow RFI and post-weaning RFI are different traits (Basarab et al., 2007). Nonetheless, Arthur et al. (2004) observed a much stronger relationship $(r=0.74)$ between post-weaning RFI and feed intake of cows at four years of age. Cows producing low RFI progeny calved 5-6 days later $(\mathrm{P}<0.001)$ than cows producing medium and high RFI progeny (Basarab et al., 2007). No age of dam effects were observed indicating this effect occurred initially in first calf heifers (Basarab et al., 2007). These results are in agreement with Arthur et al. (2005) and suggest the need for the evaluation of age at puberty in animals selected for RFI.

To date, three studies have evaluated temperament as a potential source of variation in RFI. Kelly et al. (2010) reported that RFI was unrelated to docility score in Limousin cross heifers. In 464 hybrid steers classified into low, medium, and high RFI Nkrumah et al. (2007b) reported a slight tendency $(\mathrm{P}=0.10)$ for low RFI animals to have an increased chute exit velocity; however, exit velocity was unrelated to RFI in Angus, Brahman, and Angus x Brahman cross calves (Elzo et al., 2009). Although insignificant, the potential for temperamental differences in efficiency is intriguing as overall physical activity has been reported to contribute 10 percent of the observed variation in RFI (Richardson and Herd, 2004). 


\section{Physiological Mechanisms-A Potential Explanation}

Published heritability estimates for RFI range from 0.16 (Herd and Bishop, 2000) to 0.49 (Hoque et al., 2010) with most recent estimates in the range of 0.30 to 0.40 . Although genetics and possibly breed (Schenkel et al., 2004; Elzo et al., 2009) are responsible for a substantial portion of observed differences in RFI, a significant amount of variation in RFI is due to factors other than genetics, some of which may have genetic influence but are not yet well understood.

Several reports in the literature have noted differences in feeding behavior between RFI classes. Nkrumah et al. (2007b) reported a moderate positive correlation (r $=0.49$ ) between feeding duration and RFI in crossbred steers. Additionally, high RFI animals fed more frequently (31.50 events/d) than low RFI steers (27.24 events/d) with medium RFI steers (30.36 events/d) being intermediate. Bingham et al. (2009) analyzed taped recordings of Brangus heifers feeding from individual stalls, and contrary to Nkrumah et al. (2007b), observed no difference between high and low RFI animals in meal duration or frequency. However, high RFI heifers ate more often (119.1 vs. 90.5 events/d) and ate at a faster rate (101.6 vs. $62.4 \mathrm{~g} / \mathrm{min})$ than low RFI heifers. In agreement with these reports, Robinson and Oddy (2004) reported a tendency for low RFI animals to eat fewer meals per day in both steers and heifers. A positive association between RFI and both eating rate $(r=0.26)$ and feeding events $(r=0.45)$ was reported in Holstein x Limousin cross heifers (Kelly et al., 2010). Synthesis of these reports yields agreement with the fact that high RFI animals consume more feed than low RFI animals both in confinement (Arthur et al., 2001a) and on pasture (Meyer et al., 2008). It is suggested that this is achieved either by eating more frequently or at a greater rate of 
consumption; however, in a review, Richardson and Herd (2004) reported that feeding patterns accounted for only 2 percent of the variation in RFI.

Indicators of metabolic differences based upon RFI classification have recently been investigated. Using metabolism crates and indirect calorimetry, Nkrumah et al. (2006) noted a positive correlation between RFI and methane and heat production $(\mathrm{r}=$ 0.44 and 0.68 , respectively) and a negative correlation with retained energy $(r=-0.67)$. These data suggest the potential for differences in visceral organ mass; however, studies by Cruz et al. (2010) and Mader et al. (2009) found no difference in visceral organ mass due to RFI classification and Richardson et al. (2001) reported no difference in heat production. Nonetheless, it is likely that at least part of the variation in RFI can be explained by the general processes of energy metabolism.

High RFI animals exhibited greater serum concentrations of glucose (Richardson et al., 2004 and Kolath et al., 2006a), insulin (Richardson et al., 2004), non-esterified fatty acids (Kelly et al., 2010), and $\beta$-hydroxybutyrate (Richardson et al., 2004 and Kelly et al., 2010). Castro Bulle et al. (2007) noted that maintenance energy requirements of crossbred steers increased $0.0166 \mathrm{Mcal} / \mathrm{BW}^{0.75} / \mathrm{day}$ for each one percent increase in fractional protein degradation rate, although no differences in low and high RFI animals were observed in protein synthesis or degradation. Conversely, a positive relationship with aspartate aminotransferase and both urea and plasma protein was reported by Richardson et al. (2004) and is indicative of a greater rate of protein turnover in high RFI animals. Bottje and Carstens (2009) observed similar results in poultry and hypothesized that an increase in protein turnover was due to the uncoupling of oxidative phosphorylation from electron transport, resulting in the production of reactive oxygen 
species and increased protein oxidation. However, Kolath et al. (2006a) observed no difference in low and high RFI animals with respect to mitochondrial electron leak but did report a greater coupling of oxidative phosphorylation and respiration resulting in more efficient electron transfer in low RFI steers. Additional evidence for the inefficiency of electron transport is provided by Richardson et al. (2002) who reported that high RFI bulls and heifers have larger red blood cells, more hemoglobin and, as a result, an increased oxygen carrying capacity and requirement. Logically, Kolath et al. (2006b) and Sherman et al. (2008) examined mitochondrial uncoupling protein concentration and expression, respectively, and observed no differences due to RFI classification. Reviews by Richardson and Herd (2004) and Herd and Arthur (2009) have indicated that protein turnover, tissue metabolism and stress account for 37 percent of the biological basis for RFI.

Other authors have investigated known regulators of feed intake and metabolism. Nkrumah et al. (2007a) reported that serum leptin concentrations increased with increasing RFI. Similar results were obtained by Richardson et al. (2004); however, genetic expression of the neurotransmitters regulated by leptin was not different between RFI classes (Sherman et al., 2008). Insulin-like growth factor-I (IGF-1), a known regulator of intermediary metabolism, was positively related to FCR and ADG (Stick et al., 1998), but IGF-1 was not a good indicator of differences in RFI (Lancaster et al., 2008).

Identification of genetically superior animals for RFI will require further investigation into the underlying processes that dictate differences in biological efficiency to prevent antagonistic or potentially detrimental selection decisions. From the data 
present in the literature, it is apparent that our understanding of the biological basis for RFI is expanding but somewhat limited at this time. Synthesis of the available literature reveals biological contributions to variation in RFI as presented in Figure 1.

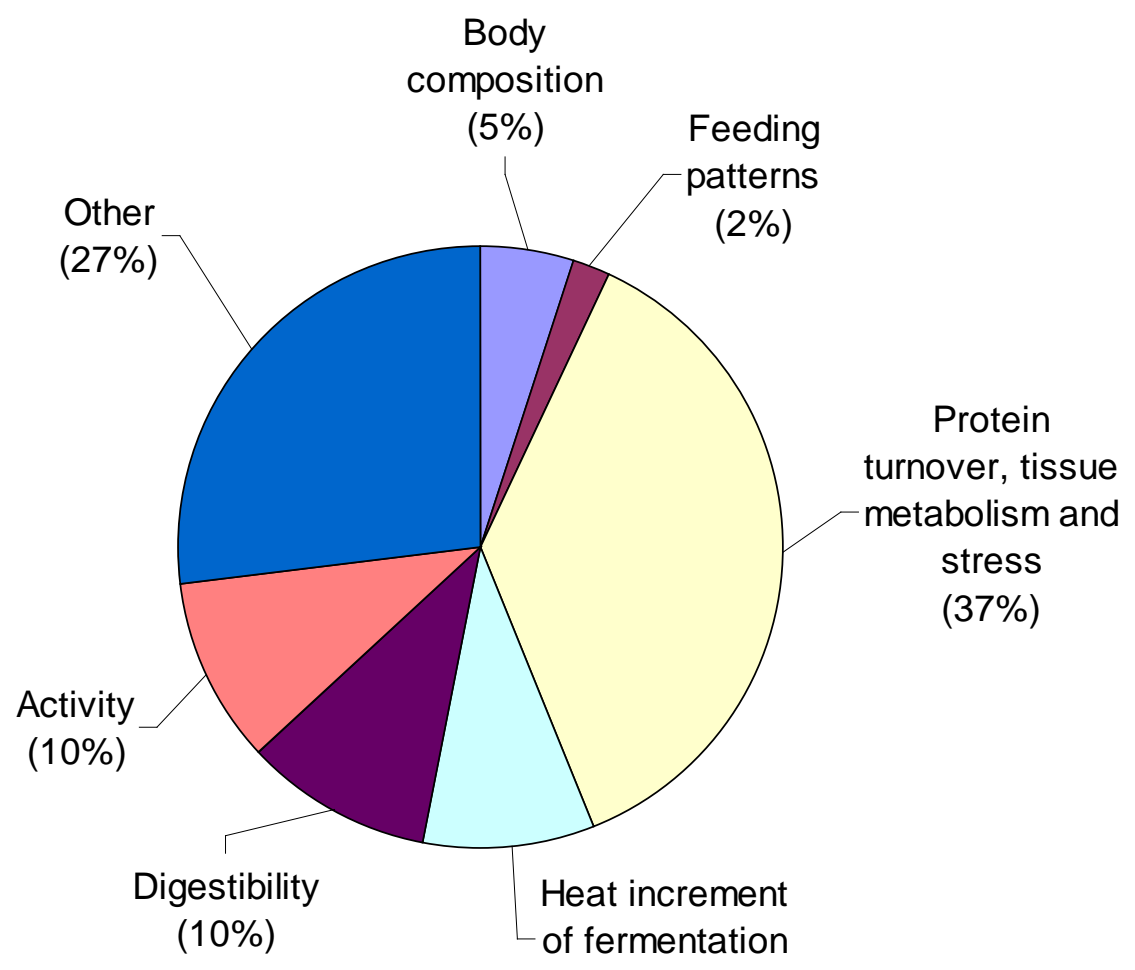

(9\%)

Figure 1. Contributions of biological mechanisms to variation in residual feed intake as determined from experiments on divergently selected cattle. Adapted from Richardson and Herd (2004). 


\section{INDUCTION OF PUBERTY}

The goal of most beef cattle management systems is to develop replacement females to breed at 14 to 16 months of age and calve at approximately two years of age. Heifers that achieve that goal and conceive early in their first breeding season calve earlier and produce more and heavier calves over their productive lifetime (Lesmeister et

al., 1973). In order to do so, heifers should experience two to three estrous cycles prior to breeding as the fertility of the first estrus is lower than that of subsequent estrous periods (Byerley et al., 1987), meaning heifers must reach puberty at around 12 months of age to achieve optimal reproductive performance.

Age at puberty is a major determinant of lifetime reproductive efficiency of beef females (Schillo et al., 1992). The onset of puberty is controlled by a complex of factors including genetics, environment, nutritional status, and season, which will be reviewed in brief. A representation of these effects and their influence on the functional competence of the hypothalamic-pituitary-gonadal axis is presented in Figure 2. 


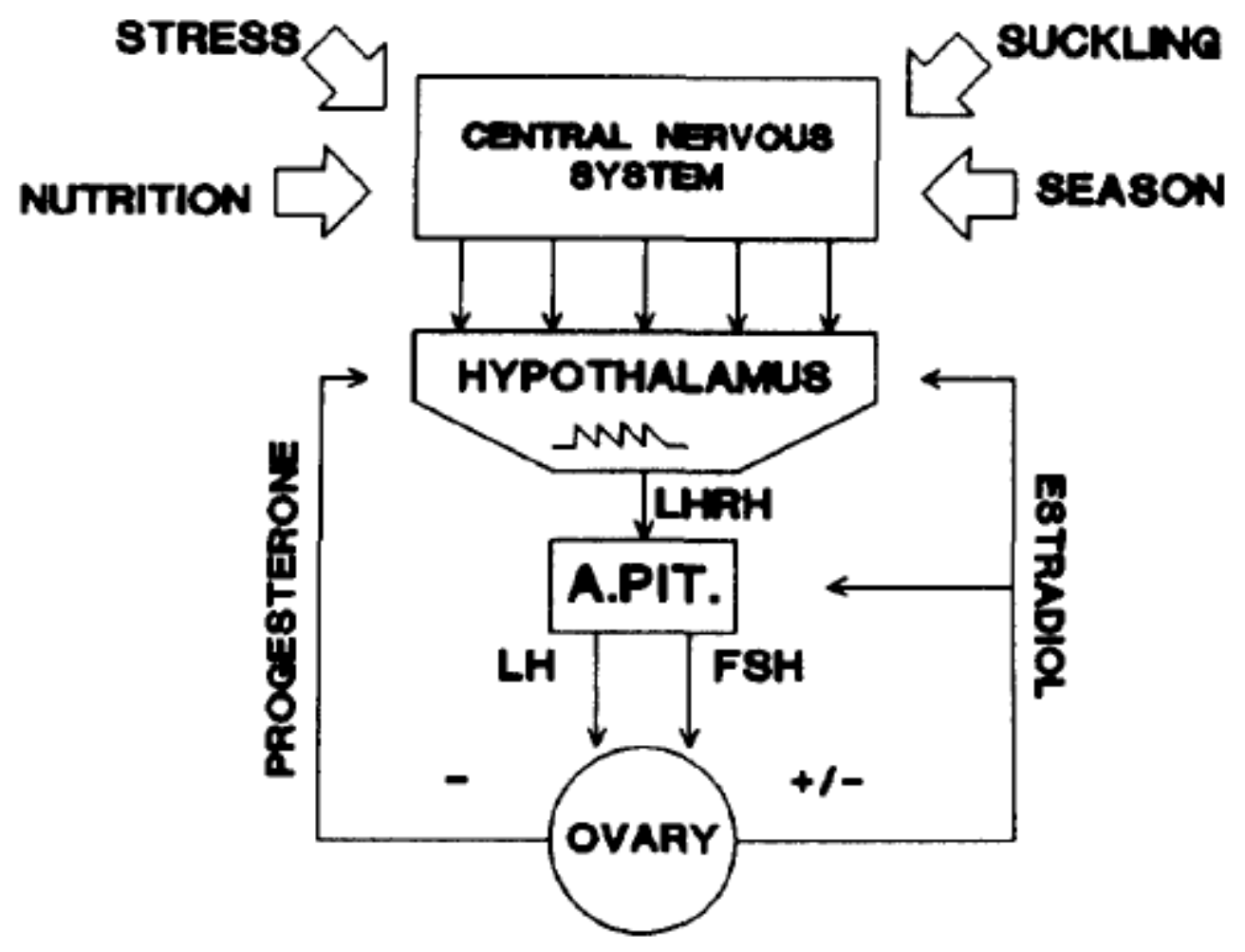

Figure 2. Schematic illustration of the hypothalamic-pituitary-ovarian axis showing neuronal and endocrine inputs that control the release of luteinizing hormone and follicle stimulating hormone. From Schillo et al. (1992).

\section{Genetics}

Breed differences exist in beef cattle in age and weight at puberty (Joubert, 1963). European breeds tend to reach puberty at an earlier age than tropical breeds (Reynolds et al., 1963; Dow et al., 1982) with considerable variation within breed (Berardinelli, 1976). Reynolds et al. (1963) observed that ages at first estrus for Angus, Brahman, and reciprocal cross heifers were 433, 816 and 460 days, respectively. Ferrell (1982) and Laster et al. (1972) also noted breed differences in age and weight at puberty with Angus and Hereford heifers reaching puberty at a greater age than Charolais, Simmental, Brown Swiss, Jersey, South Devon, Limousin, and Red Poll heifers. Ferrell (1982) reported a 
significant reduction of age at puberty in crossbred heifers when compared to straight bred heifers. In agreement with these findings, Wiltbank et al. (1966) reported a significant effect of heterosis on age and weight at puberty in reciprocal crosses of Hereford, Angus, and Shorthorn heifers.

\section{Nutritional Status}

Both pre- and postweaning growth rates are inversely related to age at puberty (Wiltbank et al., 1966; Arije and Wiltbank, 1974). Short and Bellows (1971) developed heifers pre-breeding on three increasing rates of gain and reported that higher gaining heifers reached puberty earlier and at greater BW. Similarly, Buskirk et al. (1995) observed a greater percentage of pubertal heifers ( 70.9 vs $61.3 \%$; $\mathrm{P}<0.05)$ prior to the start of the breeding season when comparing heifers that had been on a higher plane of nutrition to more moderate gaining heifers. Wiltbank et al. (1985) also reported that a greater percentage of heifers developed to heavier prebreeding BW showed estrus and became pregnant in the first 20 days of the breeding season. The timing of the onset of puberty appears to be determined by the total amount of growth postweaning rather than the rate and time of growth (Schillo et a., 1992). Lynch et al. (1997) reported no differences in age or weight at puberty when comparing heifers fed for a constant rate of gain during the postweaning development period to heifers that did not gain during the first half of the period and a high rate of gain during the second. Similary, Clanton et al. (1983) developed heifers postweaning either at a constant rate of gain, a period of no gain followed by a period of high gain, or a period of high gain followed by a period of no gain and observed no differences in age at puberty, conception rate, or calf production. The responsiveness of age at puberty to plane of nutrition during the prepubertal period is 
believed to be independent of body condition but limited by a threshold BW and age (Patterson et al., 1992).

\section{Season, Environment and Other Factors}

Season of birth influences age at puberty in beef heifers (Arije and Wiltbank, 1971), and spring-born heifers reach puberty at an earlier age than heifers born during other seasons. There are, however, conflicting reports on the effect of season of birth. Angus x Holstein heifers born in autumn attained puberty at younger ages than heifers born in spring (Schillo et al., 1982). As well, spring-born heifers treated with exogenous melatonin to simulate short day length early in life reached puberty earlier than untreated control heifers (Tortonese and Inskeep, 1992). Nonetheless, seasonal influences on the timing of puberty, which may be mediated primarily by day length, are evident. Ambient temperature and other less-defined variables also influence the attainment of puberty (Schillo et al., 1992).

Artificial methods of stimulating puberty in beef heifers have been observed.

Estrus has been induced in heifers through the use of progestogens (Berardinelli, 1976). Also, it appears that male pheromones may influence gonadotropin secretion, which has been reported in other species. Berardinelli and Joshi (2005a) reported that the presence of a bull shortened the postpartum anestrous period in primiparous beef cows by 15-20 days $(\mathrm{P}<0.05)$. Similar results were obtained when cows were exposed only to bull excretory products (Berardinelli and Joshi, 2005b); however, continuous exposure of postpartum cows to bull or steer urine did not initiate resumption of luteal activity (Tauck et al., 2006). Furthermore, a greater percentage of cows directly exposed to bulls or bull excretory products became pregnant to fixed-time artificial insemination than cows not 
exposed to bulls or bull excretory products (Berardinelli et al., 2007; Tauck and Berardinelli, 2007). Nonetheless, reports on the influence of the presence of a mature male or male urine are inconsistent in beef heifers and possible mechanisms of action are unknown (Patterson et al., 1992).

\section{Hormonal Regulation}

"The components of the reproductive endocrine axis are functional long before the onset of puberty” (Schillo et al., 1992), and yet estrus does not occur. Suppression of estrus is caused by the negative feedback of estradiol on the hypothalamus, which down regulates luteinizing hormone (LH) secretion and is decreased with age (Schillo et al., 1992). An increase in LH pulse frequency is believed to be the rate-limiting step in the attainment of puberty.

Follicular growth to the preovulatory stage does not occur in prepubertal females due to low LH pulse frequency. Physiological maturation yields a decreased hypothalamic responsiveness to negative feedback by estradiol followed by an increase in LH pulse frequency. Increased concentrations of LH stimulate follicular growth, resulting in increased levels of estradiol. Estradiol induces the preovulatory surge of LH and estrus, which may or may not be accompanied by ovulation. Subsequent estrous periods will be followed by ovulation and estrous cycles of normal length (Schillo et al., 1992). A model of the hormonal control of the onset of puberty is presented in Figure 3. 


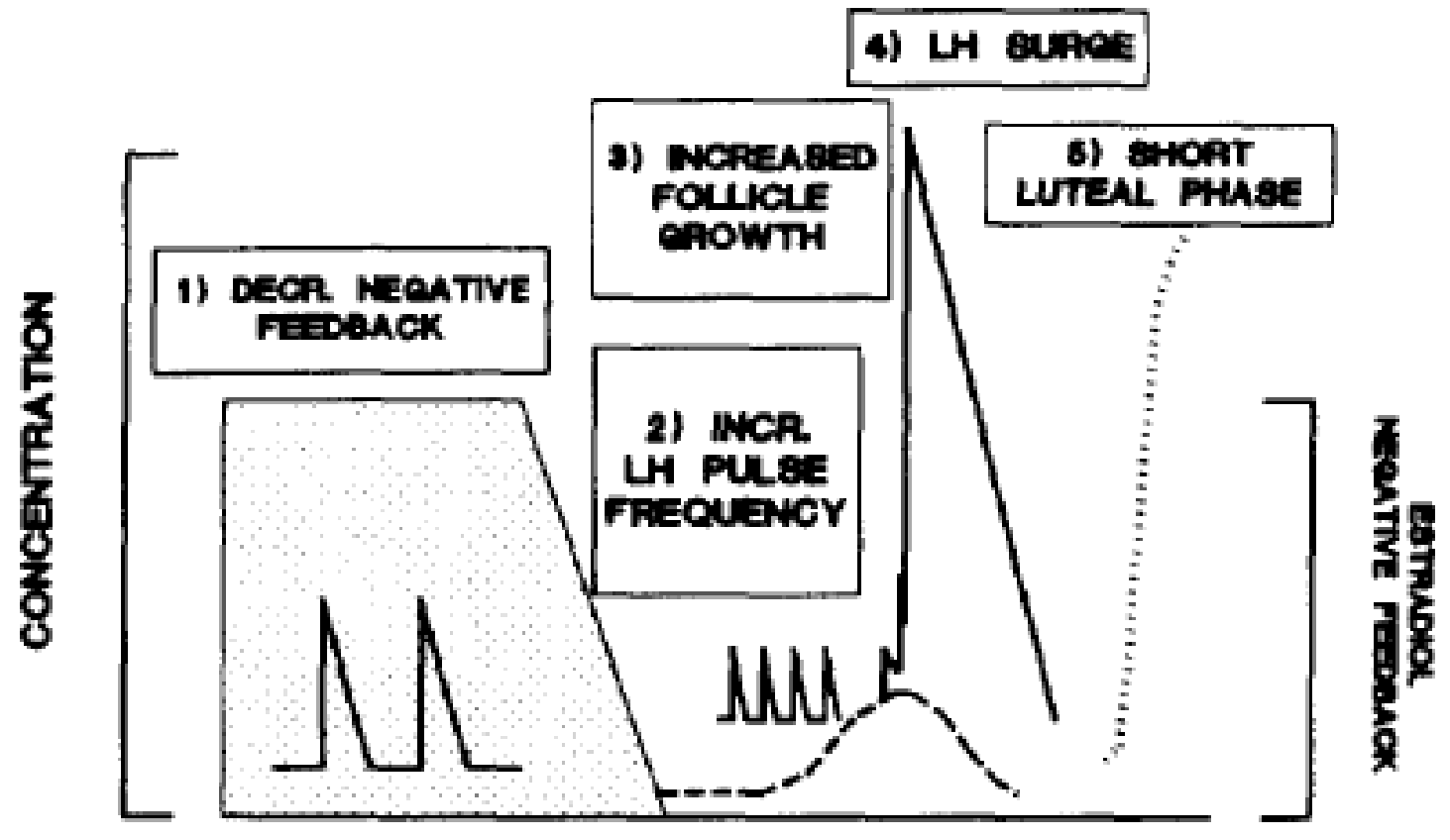

Figure 3. Summary of important endocrine events associated with onset of puberty in the heifer. Patterns of LH, estradiol, and progesterone are represented by the solid, dashed, and dotted lines, respectively. The shaded area represents degree of responsiveness of the hypothalamic-pituitary axis to estradiol negative feedback. From Schillo et al. (1992). 


\section{STATEMENT OF PROBLEM AND OBJECTIVES}

As input costs in beef production continue to rise, it becomes increasingly important to focus on efficiency, not only of feed conversion but also of reproduction. These two management areas represent the greatest proportion of input costs and/or potential profit loss in modern cow/calf production systems (Koots and Gibson, 1998).

As such, slight improvements can result in significantly decreased input costs and a greater profit margin.

Feed conversion efficiency is most often calculated as feed:gain ratio. Selection for improved efficiency by decreasing feed:gain ratio is not independent of other traits and results in increased gain performance along with an increase in mature size and feed intake of mature females (Herd and Bishop, 2000). An increase in mature size may also result in a delay in the onset of puberty, resulting in a subsequent reduction in the lifetime productivity of replacement females (Lesmeister et al., 1973). Alternatively, Koch et al. (1963) introduced the concept of residual feed intake as a measure of efficiency of feed utilization, a measure independent of body weight, weight gain, and mature size; however, only recent advances in technology and computing have made possible the calculation of RFI in scale. Recent investigations of cow/calf production system efficiency have noted that cows selected for low RFI (Arthur et al., 2005) and cows producing low RFI progeny (Basarab et al., 2007) calved 5-6 days later in the calving season, an effect that was attributed to a delay in first estrus. Therefore, the objective of this study was to evaluate the potential relationship between residual feed intake and fertility as determined by age at puberty and conception rate in yearling beef females. As 
a second objective, the relationships between residual feed intake and phenotypic measures of body composition and mature size were evaluated. 


\section{MATERIALS AND METHODS}

Studies were conducted over a two-year period from February through July with two experimental replicates (Figure 4.). After adjusting for year and farm of origin, the data were combined to enhance the usefullness of the data set. Heifers were evaluated for feed efficiency, measured as residual feed intake (RFI), and fertility to examine the potential relationship between these economically important traits.

\section{Animals}

The data were collected using 137 spring born yearling beef heifers $(\mathrm{N}=67$ year 1, $N=70$ year 2) from the West Virginia University commercial and purebred beef herds. Heifers consisted of British breed types, being predominately Angus and Angus-Cross females. Heifers were between 11 and 14 months of age in both years at trial initiation. Heifers were developed post-weaning on forage at the Wardensville farm unit in year 1 and at the Reedsville farm unit in year 2.

Approximately two weeks prior to the initiation of the trial period, heifers were gathered and transported to WVU Reymann Memorial Farm Wardensville Experiment Station. Prior to entry into the test facility, they were fitted with a radio frequency identification transponder encased in a plastic tag (Allflex USA, Inc., Dallas-Fort Worth, Texas). Upon arrival, heifers were introduced to a sorghum-sudan grass silage-based diet and were given access to four outdoor pens, each measuring 14.6 meters by 51.2 meters, with an area of 14.6 meters by 10.7 meters under roof.

All procedures and facilities used in this study were approved by the West Virginia University Animal Care and Use Committee. 


\section{Data Collection and Test Procedures}

Individual body weight (BW) was recorded upon arrival at the facility and at weekly intervals for the remainder of the trial period (84d in year 1; 71d in year 2) with weights taken on two consecutive days at initiation and conclusion of the trial. Hip height (HH) measurements were collected (d 1, 28, 56, and 84 in year 1; d -14, 14, 42, and 70) to be used in the determination of mature frame score as calculated by the Beef Improvement Federation (2002) guidelines. The resulting four age adjusted frame score measurements were then averaged to determine mean frame score (MFS). Body condition scores (BCS; scale 1 to 9; 1 = extremely thin, 9 = obese; Wagner et al., 1988) were assigned to each animal at trial initiation and conclusion by the same evaluator. Standard carcass ultrasound measures were collected at trial initiation and conclusion to evaluate changes in body composition. The data were collected by a Certified Ultrasound Processing Laboratory technician using a real-time B-mode ultrasound scanner (Aloka Corometrics Medical System, Wallangfor, CT) equipped with a linear-array $5 \mathrm{MHz}$ transducer. Subcutaneous rump fat (RUF), subcutaneous rib fat (RIF), longissimus muscle area (LMA), and intramuscular fat (IMF) data were obtained. Individual feed intake data were collected utilizing the GrowSafe 3000E system (GrowSafe Systems, Ltd., Airdrie, Alberta, Canada) for the duration of the trial period and were used in the calculation of RFI. 


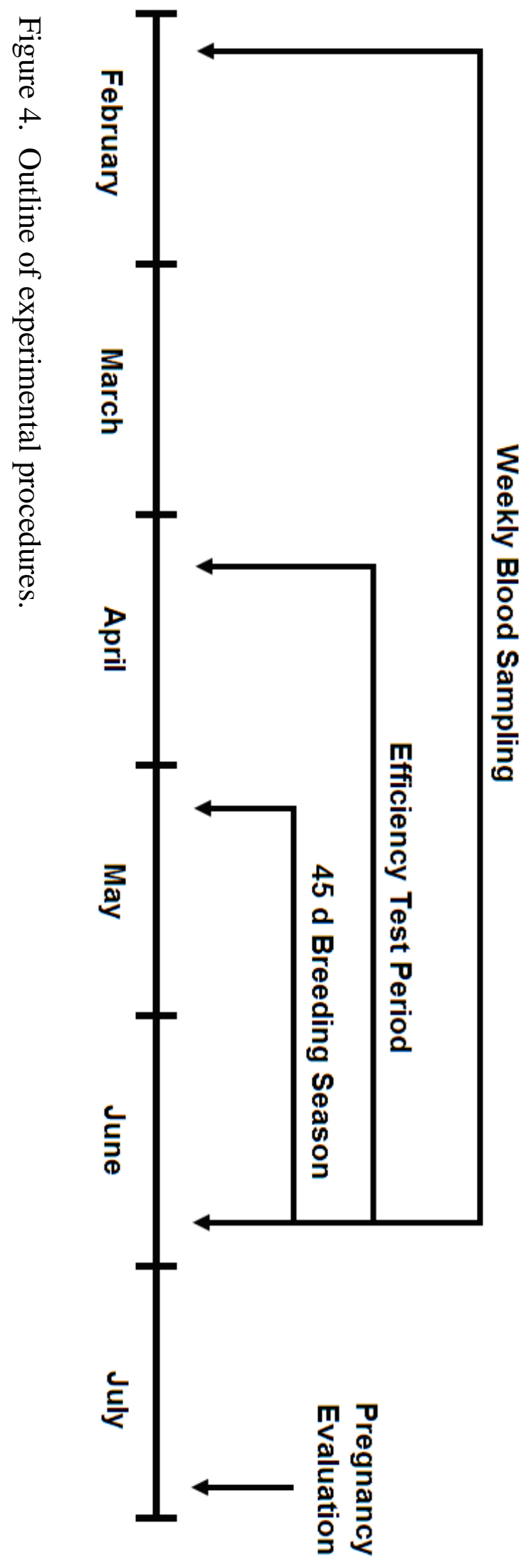




\section{Diets}

Diets were formulated according to NRC (2000) recommendations for growing cattle and were designed for $0.45 \mathrm{~kg} /$ day gain. Due to limited supply of feedstuffs in year 1, heifers received two diets during the trial period (Table 1). Diet 1 was fed d 0 through d 51. A transition period consisting of a combination of 50\% Diet 1 and $50 \%$ Diet 2 was fed on d 52 through d 63, and the trial was completed (d 64 through d 84) on Diet 2. A single diet was fed in year 2. All diets were fed ad libitum.

Table 1. Composition and Nutrient Analysis of Diets

\begin{tabular}{|l|c|c|c|}
\hline \multirow{2}{*}{$\begin{array}{c}\text { Ingredient } \\
\text { (\%AF) }\end{array}$} & \multicolumn{2}{c|}{ Year 1 } & Year 2 \\
\cline { 2 - 4 } & Diet 1 & Diet 2 & \\
\hline Sorghum/Sudan Silage & 55.9 & -- & 68.1 \\
\hline Corn Silage & -- & 50.0 & -- \\
\hline Grass Hay & 25.7 & 33.5 & 21.3 \\
\hline Supplement & ab & 16.4 & \\
\hline \multicolumn{4}{|c|}{ Nutrient Analysis ${ }^{\mathrm{c}}$} \\
\hline Dry Matter & 47.42 & 59.44 & 47.84 \\
\hline Ash & 8.45 & 6.40 & 11.21 \\
\hline Crude Protein & 10.86 & 9.66 & 10.57 \\
\hline NDF & 53.15 & 64.74 & 59.35 \\
\hline NDF Crude Protein & 4.76 & 5.90 & 5.35 \\
\hline ADF & 26.08 & 32.18 & 33.84 \\
\hline ADF Crude Protein & 1.00 & 1.08 & 0.54 \\
\hline Soluble Protein & 1.81 & 1.83 & 1.06 \\
\hline
\end{tabular}

${ }^{a}$ Supplement for Year 1 was composed of 93.9\% ground corn, 2.26\% mineral premix, 2.19\% soybean meal, $1.51 \%$ salt, and $0.13 \%$ limestone.

b Supplement for Year 2 was composed of 49.34\% soybean hulls, $41.97 \%$ ground corn, $6.90 \%$ soybean meal, $1.13 \%$ mineral premix, $0.45 \%$ salt, and $0.23 \%$ limestone.

${ }^{\mathrm{c}}$ Values reported on a \%DM basis.

\section{Determination of Puberty}

Blood samples were obtained once weekly via tail venipuncture beginning one week prior to any heifer reaching 12 months of age (early February of both years). 
Sampling continued until the end of the trial period. Samples were refrigerated over night at which time plasma was harvested, split into two samples for individual assay, and stored at $-20^{\circ} \mathrm{C}$ until progesterone was quantified. Plasma concentrations of progesterone were determined using a commercially available individual radioimmunoassay kit. (Coat-a-Count Progesterone; Siemens Medical Solutions Diagnostics, Dallas, TX). Heifers were considered pubertal when progesterone concentrations exceeded $1 \mathrm{ng} / \mathrm{ml}$. Individual assay was discontinued when this criterion was met.

\section{Estrous Detection and Breeding}

Seven days prior to the initiation of the breeding season (d 27) heifers were fitted with a commercial radiotelemetric, pressure-sensitive estrous detection device known as HeatWatch ${ }^{\circledR}$ (CowChips, Inc., Denver, CO). Each device was placed in a saddle-type patch and glued just anterior to the tailhead using a commercially available biodegradable adhesive. The pressure sensor was activated by the weight of a mounting female, which sent a radio frequency transmission signal to a computer via a stationary antenna mounted adjacent to the drylot pens housing the heifers. The signal transmitted heifer identification, date, time, and duration of mounting activity. These data along with observation twice daily for visual signs of estrus (minimum of $30 \mathrm{~min}$ ) at 0700 and 1900 $\mathrm{h}$ were used in the determination of standing estrus. Following determination of estrus, heifers were artificially inseminated according to the AM-PM rule (12-16 h after first observation of standing estrus) by one of two experienced technicians using frozen/thawed semen from one commercially available Angus sire. Timing of inseminations was based on the initial mount of the estrous period as determined by the 
HeatWatch ${ }^{\circledR}$ system. A 45-day breeding season was utilized in both years beginning on day 34 in year 1 and day 21 in year 2 . Breeding concluded at the end of the trial period in both years. No estrous synchronization techniques were employed in this experiment.

\section{Pregnancy Determination}

First service conception rate and overall pregnancy rate were determined via transrectal ultrasonography by an experienced technician using a real-time B-mode ultrasound scanner (Aloka 500, Corometrics Medical Systems) equipped with a linear array 5.0 MHz transducer $30 \mathrm{~d}$ after the conclusion of the breeding season.

\section{Determination of RFI}

Individual feed intake data were collected over 84 and 70 days in years 1 and 2, respectively. In order to increase the usefulness of the data set, individual feed intakes were converted to kg of total digestible nutrients (TDN) (New York State TDN Equation-Complete Feed) to adjust for differences in dry matter consumption over both years. Intakes expressed as kg of TDN consumed per day were used to calculate RFI combining both years' data. Weekly BW for each heifer was regressed on time using simple linear regression to calculate beginning BW, mid-test weight, and ADG. Heifer ADG and

metabolic mid-test weight $\left(\mathbf{M M T W}\right.$; = mid-test weight $\left.{ }^{0.75}\right)$ were regressed against individual average daily intake and RFI was calculated as the residual, or the difference between the predicted value of the regression and the actual measured value based on the following equation:

$$
\text { RFI }=\text { Intake }-[2.55861+(0.02442 * M M T W)+(1.98698 * A D G)]
$$




\section{Statistical Analyses}

The data were analyzed with heifer as the experimental unit, with heifers classified into groups based upon RFI rank. Differences in BW, MFS, BCS, RIF, RUF, IMF, and LMA between negative (NEG; n=69) and positive (POS; n=68) and among low (LOW; n=29), medium (MED; n=43), and high (HIGH; n=35) RFI heifers $(<0.5, \pm$ 0.5, and $>0.5$ SD from the mean, respectively) were analyzed using the general linear model (GLM) procedure of SAS (SAS Institute; Cary, NC, 2006). The fixed effects of year and farm were included in the model for each trait analyzed. With respect to end of test and gain in body composition, the model contained as covariates those measures of composition for which on test differences were detected. Phenotypic relationships between RFI and measured traits were examined using the PROC CORR procedure of SAS (2006).

Age at puberty (AP) was determined as the age in days of heifers at the time serum progesterone concentrations were observed $>1 \mathrm{ng} / \mathrm{ml}$. Twenty-eight heifers were determined prepubertal at the completion of the sampling period but were utilized in the analysis of AP by including their age in days at trial conclusion plus one. As well, 25 heifers were determined pubertal during the first three sampling periods, encompassing a 21-day period and equal to the mean length of the bovine estrous cycle. Therefore, the certainty that these values are indicative of first estrus is unclear. The error associated with these measures can serve only as an overestimate of the individuals true AP, and so the determined value less one was included in the analysis. The following linear mixed model was fitted to DOAP data using the analysis of covariance model building strategy discussed in Milliken and Johnson (2002): 


$$
Y_{i j k}=\mu . .+\alpha_{i}+\beta_{j}+(\alpha \beta)_{i j}+\gamma X_{i j k}+b_{i j k}+\varepsilon_{i j k}
$$

where:

$Y_{i j k}$ are the DOAP measurments

$\mu .$. is the grand mean

$\alpha_{i}$ are the fixed year effects

$\beta_{j}$ are the fixed farm effects

$(\alpha \beta)_{i j}$ are fixed year-by-farm interaction effects

$\gamma$ is a constant regression coefficient for the linear relationship between $Y$ and $X$

$X_{i j k}$ are the RFI measurements

$b_{i j k}$ are random cow effects distributed as iid $N\left(0 ; \sigma^{2}{ }_{b}\right)$

$\varepsilon_{i j k}$ are random errors distributed as iid $N\left(0 ; \sigma^{2}\right)$

$i=1,2 ; j=1,2,3 ; k=1, \ldots, n_{i j}$

We assumed that there were no random interaction effects for this model. Data analysis was generated using Proc Mixed from SAS software, Version 9.2 of the SAS System for Unix. Type 3 F-tests of fixed effects and the $R^{2}$ statistic of Vonesh and Chinchilli (1997) were computed. We obtained estimates of both variance components $\sigma_{b}^{2}$ and $\sigma^{2}$ along with an approximate Satterthwaite 95\% confidence interval for $\sigma_{b}^{2}$. Additionally, an estimate of the slope parameter was computed along with a 95\% $t$-based confidence interval. Random effects and residual diagnostics were run to check and verify the assumptions of the linear mixed model. 


\section{RESULTS}

\section{General}

Descriptive statistics are presented in Table 2. Heifers averaged $387 \pm 19.4$ days of age and $337 \pm 29.9 \mathrm{~kg}$ at trial initiation across both years. Heifers gained more rapidly in Year 2 than in Year 1 (1.25 vs $1.01 \mathrm{~kg} / \mathrm{d}$, respectively, $\mathrm{P}<0.001)$, but end weight did not differ $(\mathrm{P}=0.64)$ as the trial was 14 days shorter in Year 2. Overall mean ADG was $1.14 \pm 0.21 \mathrm{~kg} /$ day. Additionally, Year 1 heifers were approximately 17 days younger (P $<0.001$ ) at trial initiation, reached puberty earlier (387 vs 453 days of age, respectively, $\mathrm{P}$ $<0.001$ ), and were larger framed (Frame Score 5.6 vs 5.3, respectively, $\mathrm{P}<0.01$ ) than in Year 2.

POSITIVE and NEG RFI heifers did not differ in Age, Initial BW, Final BW, ADG, or Frame Score; however, POS RFI heifers consumed more TDN per day (7.61 vs. $6.09 \mathrm{~kg} / \mathrm{d}$, respectively, $\mathrm{P}<0.001)$ and were younger at puberty than NEG RFI heifers (414 vs. 427 d, respectively, $\mathrm{P}=0.03$ ). Even so, there was no difference in either pregnancy or conception rate between POS and NEG heifers. Descriptive statistics of POS and NEG RFI heifers are presented in Table 3.

Similarly, LOW, MEDIUM, and HIGH RFI heifers did not differ in Age, Initial BW, Final BW, or Frame Score. MEDIUM heifers did, however, gain faster (1.17 vs. 1.09 and $1.10 \mathrm{~kg} / \mathrm{d}$, respectively, $\mathrm{P}<0.05$ ) than LOW or HIGH heifers. HIGH RFI heifers consumed more TDN per day than LOW RFI heifers, with MEDIUM heifers being intermediate. Additionally, MEDIUM heifers reached puberty at a greater age (427 days of age) than HIGH RFI heifers (411 days of age) but did not differ from LOW RFI 
heifers (425 days of age). Descriptive statistics for HIGH, MEDIUM, and LOW heifers are presented in Table 4.

Table 2. Heifer descriptive statistics pooled across years.

\begin{tabular}{|l|c|c|c|c|}
\hline Trait $^{1}$ & Mean & SD & Minimum & Maximum \\
\hline Age (days) & 387.0 & 19.36 & 341 & 439 \\
\hline Initial BW (kg) & 337.0 & 29.90 & 287 & 417 \\
\hline Final BW (kg) & 423.6 & 32.95 & 357 & 509 \\
\hline ADG (kg/d) & 1.14 & 0.21 & 0.45 & 1.59 \\
\hline Intake (kg TDN/d) & 6.92 & 1.07 & 2.24 & 9.87 \\
\hline RFI (kg TDN/d) & 0.00 & 0.97 & -3.66 & 6.90 \\
\hline Frame Score & 5.46 & 0.53 & 4.35 & 497 \\
\hline Age at Puberty (Days) & 420.3 & 48.23 & 312 & \\
\hline Pregnancy Rate (\%) & 51.1 & & & \\
\hline
\end{tabular}

${ }^{1} \mathrm{BW}=$ body weight; $\mathrm{ADG}=$ average daily gain; $\mathrm{RFI}=$ residual feed intake. 
Table 3. Descriptive statistics for POSITIVE vs. NEGATIVE RFI heifers.

\begin{tabular}{|l|c|c|c|c|}
\hline Trait & POS & NEG & SEM $^{2}$ & P-value \\
\hline $\mathrm{N}$ & 68 & 69 & \multicolumn{2}{|l|}{} \\
\hline Age (days) & 387 & 386 & 2.47 & 0.78 \\
\hline Initial BW (kg) & 335 & 338 & 4.07 & 0.53 \\
\hline Final BW (kg) & 421 & 425 & 4.31 & 0.48 \\
\hline ADG (kg/d) & 1.12 & 1.14 & 0.02 & 0.50 \\
\hline Intake (kg TDN/d) & 7.61 & 6.09 & 0.10 & $<0.001$ \\
\hline RFI (kg TDN/d) & 0.73 & -0.85 & 0.09 & $<0.001$ \\
\hline Frame Score & 5.43 & 5.45 & 0.08 & 0.83 \\
\hline Age at Puberty (days) & 414 & 427 & 4.67 & 0.03 \\
\hline Pregnancy Rate (\%) & 58.8 & 43.5 & & 0.19 \\
\hline Conception Rate (\%) & 71.4 & 58.8 & & 0.17 \\
\hline
\end{tabular}

${ }^{1} \mathrm{BW}=$ body weight; $\mathrm{ADG}$ = average daily gain; RFI = residual feed intake.

${ }^{2}$ Pooled standard error of treatment means. 
Table 4. Descriptive statistics for HIGH, MEDIUM and LOW RFI heifers.

\begin{tabular}{|c|c|c|c|c|c|}
\hline \multirow{2}{*}{ Trait $^{2}$} & \multicolumn{3}{|c|}{ RFI Classification ${ }^{1}$} & \multirow{2}{*}{ SEM $^{3}$} & \multirow{2}{*}{ P-value } \\
\hline & HIGH & MEDIUM & LOW & & \\
\hline $\mathrm{N}$ & 42 & 56 & 39 & & \\
\hline Age (days) & 386 & 387 & 385 & 3.25 & 0.60 \\
\hline Initial BW (kg) & 334 & 332 & 340 & 5.19 & 0.20 \\
\hline Final BW (kg) & 418 & 422 & 423 & 5.53 & 0.48 \\
\hline $\mathrm{ADG}(\mathrm{kg} / \mathrm{d})$ & $1.10^{\mathrm{a}}$ & $1.17^{\mathrm{b}}$ & $1.09^{\mathrm{a}}$ & 0.03 & $<0.05$ \\
\hline Intake (kg TDN/d) & $7.82^{\mathrm{c}}$ & $6.98^{b}$ & $5.56^{\mathrm{a}}$ & 0.11 & $<0.001$ \\
\hline RFI (kg TDN/d) & $1.00^{\mathrm{C}}$ & $0.00^{\mathrm{b}}$ & $-1.28^{\mathrm{a}}$ & 0.09 & $<0.001$ \\
\hline Frame Score & 5.48 & 5.33 & 5.52 & 0.10 & 0.13 \\
\hline Age at Puberty (days) & $411^{\mathrm{a}}$ & $427^{\mathrm{b}}$ & $425^{\mathrm{ab}}$ & 6.06 & 0.03 \\
\hline Pregnancy Rate (\%) & 54.8 & 51.8 & 46.2 & & 0.87 \\
\hline Conception Rate (\%) & 65.7 & 67.4 & 62.1 & & 0.89 \\
\hline
\end{tabular}

${ }^{1} \mathrm{HIGH}=>0.5 \mathrm{SD}$ above mean; MEDIUM $= \pm 0.5 \mathrm{SD}$ around mean; LOW $=<0.5 \mathrm{SD}$ below mean.

${ }^{2} \mathrm{BW}=$ body weight; $\mathrm{ADG}$ = average daily gain; RFI = residual feed intake.

${ }^{3}$ Pooled standard error of treatment means.

Means within row with varying superscripts are different at $\mathrm{P}<0.05$. 


\section{Body Composition}

POSITIVE heifers tended to possess more RIF $(\mathrm{P}=0.05)$ and longissimus muscle area $\left(\mathrm{cm}^{2}\right)$ per hundred kg of BW $($ LMACWT $)(\mathrm{P}=0.08)$ than NEG heifers at trial initiation, while LMACWT was greater in POS heifers at trial conclusion $(\mathrm{P}<0.01)$. No differences in final subcutaneous fat thickness, LMA or IMF were observed; however, NEG heifers tended to have a greater final BCS than POS heifers $(\mathrm{P}<0.10)$. Initial and final BCS and carcass ultrasound measures for POS and NEG heifers are presented in Table 5.

HIGH RFI heifers were not different $(\mathrm{P}>0.10)$ from LOW RFI females with respect to RIF and RUF at trial initiation, while MEDIUM heifers exhibited less RIF and RUF (P < 0.05) when compared to either HIGH or LOW. End of test measures of fatness were not different. LMACWT was less $(\mathrm{P}<0.05)$ in LOW RFI heifers when compared to HIGH but were not different $(\mathrm{P}>0.10)$ from MEDIUM females at both beginning and end of test. When compared to HIGH RFI heifers, final BCS was greater in MEDIUM and LOW RFI heifers. No other differences in body composition were observed. Initial and final BCS and ultrasound body composition data for HIGH, MEDIUM, and LOW heifers are presented in Tables 6 and 7, respectively.

Body composition change is reported in Table 8 for POS and NEG heifers and in Table 9 for HIGH, MEDIUM, and LOW heifers. The values reported are least squares means of the final minus the initial value for each trait. No differences were observed for either POS vs. NEG or HIGH, MEDIUM, or LOW heifers. 
Table 5. BCS and carcass ultrasound traits of POSITIVE and NEGATIVE RFI heifers at trial initiation and conclusion.

\begin{tabular}{|l|c|c|c|c|c|c|}
\hline \multirow{2}{*}{ Trait $^{1}$} & \multicolumn{3}{|c|}{ Initial } & \multicolumn{3}{c|}{ Final } \\
\cline { 2 - 7 } & POS & NEG & SEM $^{2}$ & POS & NEG & SEM $^{2}$ \\
\hline BCS & 6.23 & 6.17 & 0.07 & 6.41 & 6.55 & $0.06^{\dagger}$ \\
\hline RUF (mm) & 40.7 & 37.7 & 2.62 & 64.9 & 60.9 & 2.28 \\
\hline RIF (mm) & 40.0 & 36.7 & $1.32^{\dagger}$ & 51.9 & 49.2 & 1.66 \\
\hline IMF (\%) & 4.65 & 4.72 & 0.12 & 4.44 & 4.45 & 0.12 \\
\hline LMA (cm ${ }^{2}$ ) & 51.38 & 49.77 & 0.91 & 59.83 & 57.95 & 0.94 \\
\hline LMA/CWT & 15.34 & 14.79 & $0.24^{\dagger}$ & 14.31 & 13.56 & $0.21^{*}$ \\
\hline
\end{tabular}

${ }^{1} \mathrm{BCS}=$ body condition score; RUF $=$ ultrasound rump fat; RIF $=$ ultrasound $12^{\text {th }}$ rib back fat; IMF $=\%$ intramuscular fat; LMA $=12^{\text {th }}$ rib longissimus muscle area; LMA/CWT = $12^{\text {th }}$ rib longissimus muscle area per $100 \mathrm{~kg}$ body weight.

${ }^{2}$ Pooled standard error of treatment means.

$\dagger \mathrm{P}<0.10, * \mathrm{P}<0.01$ 
Table 6. BCS and carcass ultrasound traits of HIGH, MEDIUM and LOW heifers at trial initiation.

\begin{tabular}{|l|c|c|c|c|}
\hline \multirow{2}{*}{ Trait $^{2}$} & \multicolumn{3}{|c|}{ RFI Classification $^{1}$} & \multirow{2}{*}{ SEM $^{3}$} \\
\cline { 2 - 5 } & HIGH & MED & LOW & \\
\hline BCS & 6.25 & 6.19 & 6.18 & 0.08 \\
\hline RUF (mm) & $43.0^{\mathrm{b}}$ & $36.3^{\mathrm{a}}$ & $40.2^{\mathrm{ab}}$ & 2.68 \\
\hline RIF (mm) & $41.2^{\mathrm{b}}$ & $37.2^{\mathrm{a}}$ & $38.0^{\mathrm{ab}}$ & 1.56 \\
\hline IMF (\%) & 4.58 & 4.61 & 4.89 & 0.16 \\
\hline LMA (cm $\left.{ }^{2}\right)$ & 51.59 & 50.07 & 50.52 & 1.08 \\
\hline LMA/CWT & 15.40 & 15.26 & $14.71^{\dagger}$ & 0.02 \\
\hline
\end{tabular}

${ }^{1} \mathrm{HIGH}=>0.5 \mathrm{SD}$ above mean; MEDIUM $= \pm 0.5 \mathrm{SD}$ around mean; LOW $=<0.5 \mathrm{SD}$ below mean.

${ }^{2} \mathrm{BCS}=$ body condition score; RUF = ultrasound rump fat; RIF = ultrasound $12^{\text {th }}$ rib back fat; IMF $=\%$ intramuscular fat; LMA $=12^{\text {th }}$ rib longissimus muscle area; LMA/CWT = $12^{\text {th }}$ rib longissimus muscle area per $100 \mathrm{~kg}$ body weight.

${ }^{3}$ Pooled standard error of treatment means.

Means within row with varying superscripts are different at $\mathrm{P}<0.05$. $† \mathrm{P}<0.10$. 
Table 7. BCS and carcass ultrasound traits of HIGH, MEDIUM and LOW heifers at trial conclusion.

\begin{tabular}{|l|c|c|c|c|}
\hline \multirow{2}{*}{ Trait $^{2}$} & \multicolumn{3}{|c|}{ RFI Classification $^{1}$} & \multirow{2}{*}{ SEM $^{3}$} \\
\cline { 2 - 5 } & HIGH & MED & LOW & \\
\hline BCS & $6.32^{\mathrm{a}}$ & $6.52^{\mathrm{b}}$ & $6.57^{\mathrm{b}}$ & 0.08 \\
\hline RUF (mm) & 63.8 & 65.1 & 60.8 & 2.90 \\
\hline RIF (mm) & 50.6 & 52.0 & 50.7 & 2.50 \\
\hline IMF (\%) & 4.36 & 4.47 & 4.31 & 0.17 \\
\hline LMA (cm $\left.{ }^{2}\right)$ & 59.10 & 60.27 & 58.60 & 1.38 \\
\hline LMA/CWT & $14.26^{\mathrm{b}}$ & $14.26^{\mathrm{b}}$ & $13.41^{\mathrm{a}}$ & 0.02 \\
\hline
\end{tabular}

${ }^{1} \mathrm{HIGH}=>0.5 \mathrm{SD}$ above mean; MEDIUM $= \pm 0.5 \mathrm{SD}$ around mean; $\mathrm{LOW}=<0.5 \mathrm{SD}$ below mean.

${ }^{2} \mathrm{BCS}=$ body condition score; RUF = ultrasound rump fat; RIF = ultrasound $12^{\text {th }}$ rib back fat; $\mathrm{IMF}=\%$ intramuscular fat; $\mathrm{LMA}=12^{\text {th }}$ rib longissimus muscle area; LMA/CWT = $12^{\text {th }}$ rib longissimus muscle area per $100 \mathrm{~kg}$ body weight.

${ }^{3}$ Pooled standard error of treatment means.

Means within row with varying superscripts are different at $\mathrm{P}<0.05$. 
Table 8. Change in (final - initial) carcass ultrasound traits of POSITIVE and NEGATIVE RFI heifers.

\begin{tabular}{|l|c|c|c|c|}
\hline Trait $^{1}$ & POS & NEG & SEM $^{2}$ & P-value \\
\hline$\Delta$ RUF $(\mathrm{mm})$ & 25.29 & 23.44 & 2.87 & 0.58 \\
\hline$\Delta \mathrm{RIF}(\mathrm{mm})$ & 13.06 & 10.28 & 1.66 & 0.20 \\
\hline$\Delta \mathrm{IMF}(\%)$ & -0.20 & -0.28 & 0.13 & 0.60 \\
\hline$\Delta \mathrm{LMA}\left(\mathrm{cm}^{2}\right)$ & 8.80 & 7.52 & 0.72 & 0.17 \\
\hline$\Delta$ LMA/CWT & -1.01 & -1.28 & 0.21 & 0.33 \\
\hline
\end{tabular}

${ }^{1}$ RUF = ultrasound rump fat; RIF = ultrasound $12^{\text {th }}$ rib back fat; IMF $=\%$ intramuscular fat; LMA $=12^{\text {th }}$ rib longissimus muscle area; LMA $/ C W T=12^{\text {th }}$ rib longissimus muscle area per $100 \mathrm{~kg}$ body weight.

${ }^{2}$ Pooled standard error of treatment means.

Table 9. Change in (final - initial) carcass ultrasound traits of HIGH, MEDIUM and LOW heifers.

\begin{tabular}{|l|c|c|c|c|}
\hline \multirow{2}{*}{ Trait $^{2}$} & \multicolumn{3}{|c|}{ RFI Classification $^{1}$} & \multirow{2}{*}{ SEM $^{3}$} \\
\cline { 2 - 5 } & HIGH & MEDIUM & LOW & \\
\hline$\Delta$ RUF (mm) & 24.64 & 25.82 & 21.57 & 2.90 \\
\hline$\Delta$ RIF (mm) & 11.30 & 13.10 & 12.01 & 2.31 \\
\hline$\Delta \mathrm{IMF}(\%)$ & -0.18 & -0.18 & -0.39 & 0.18 \\
\hline$\Delta$ LMA $\left(\mathrm{cm}^{2}\right)$ & 8.21 & 9.25 & 7.30 & 1.07 \\
\hline$\Delta$ LMA/CWT & -1.09 & -1.02 & -1.29 & 0.31 \\
\hline
\end{tabular}

${ }^{1} \mathrm{HIGH}=>0.5 \mathrm{SD}$ above mean; MEDIUM $= \pm 0.5 \mathrm{SD}$ around mean; LOW $=<0.5 \mathrm{SD}$ below mean.

${ }^{2}$ RUF $=$ ultrasound rump fat; RIF $=$ ultrasound $12^{\text {th }}$ rib back fat; IMF $=\%$ intramuscular fat; LMA $=12^{\text {th }}$ rib longissimus muscle area; LMA $/ C W T=12^{\text {th }}$ rib longissimus muscle area per $100 \mathrm{~kg}$ body weight.

${ }^{3}$ Pooled standard error of treatment means.

Means within row with varying superscripts are different at $\mathrm{P}<0.05$. 


\section{Production Trait Relationships}

Pearson correlation coefficients for RFI and measures of growth, feed intake, and mature size are presented in Table 10. As expected, a strong positive relationship between RFI and TDN Intake $(r=0.91, \mathrm{P}<0.001)$ was observed. RFI was not correlated with ADG, Initial BW, Final BW, or MFS, but tended to have a slight negative relationship with AP $(r=-0.16, \mathrm{P}<0.10)$. Interestingly, a small negative relationship existed between AP and FS ( $\mathrm{r}=-0.29, \mathrm{P}<0.001)$. FS was positively correlated with both Initial and Final BW ( $\mathrm{r}=0.37$ and 0.40 , respectively, $\mathrm{P}<0.001$ ) but unrelated to ADG; however, ADG was positively correlated with TDN Intake $(r=0.41, \mathrm{P}<0.001)$. A slight relationship $(\mathrm{P}<0.05)$ existed between RFI and both RIF and RUF $(r=0.19$ and 0.17 , respectively, $\mathrm{P}<0.05)$ initially and strengthened to $\mathrm{r}=0.27$ and $\mathrm{r}=0.24(\mathrm{P}<0.01)$, respectively, at trial conclusion. RFI tended $(\mathrm{P}<0.10)$ to be slightly positively related to LMACWT initially, but was not at trial conclusion. Additionally, a slight positive relationship existed between RFI and gain in RIF ( $\mathrm{r}=0.18, \mathrm{P}<0.05)$. As expected, measures of subcutaneous fat thickness were highly related at all stages yet were unrelated to IMF. A moderate positive relationship existed between LMA, initial and final RIF and RUF and gain in RIF and RUF. Phenotypic correlations for RFI with initial, final, and gain in measures of body composition are presented in Tables 11, 12 and 13 , respectively. 
Table 10. Phenotypic correlations of RFI with measures of performance, intake, and mature size.

\begin{tabular}{|c|c|c|c|c|c|c|c|}
\hline Trait $^{1}$ & $\begin{array}{c}\text { TDN } \\
\text { Intake }\end{array}$ & $\mathrm{ADG}$ & Initial BW & Final BW & $\begin{array}{l}\text { Frame } \\
\text { Score }\end{array}$ & $\begin{array}{l}\text { Age at } \\
\text { Puberty }\end{array}$ & RFI \\
\hline TDN Intake & 1.00 & $0.41^{* * *}$ & 0.08 & $0.26 * *$ & 0.05 & 0.05 & $0.91 * * *$ \\
\hline $\mathrm{ADG}$ & & 1.00 & -0.03 & $0.32 * * *$ & -0.01 & $0.48 * * *$ & 0.00 \\
\hline Initial BW & & & 1.00 & $0.91 * * *$ & $0.37 * * *$ & 0.00 & -0.02 \\
\hline Final BW & & & & 1.00 & $0.40 * * *$ & 0.08 & 0.02 \\
\hline Frame Score & & & & & 1.00 & $-0.29 * * *$ & 0.01 \\
\hline $\begin{array}{l}\text { Age at } \\
\text { Puberty }\end{array}$ & & & & & & 1.00 & $-0.16^{\dagger}$ \\
\hline RFI & & & & & & & 1.00 \\
\hline
\end{tabular}

${ }^{1} \mathrm{TDN}=$ total digestible nutrients; $\mathrm{ADG}=$ average daily gain; $\mathrm{BW}=$ body weight; $\mathrm{RFI}=$ residual feed intake.

$\dagger \mathrm{P}<0.10, * \mathrm{P}<0.05, * * \mathrm{P}<0.01$, and $* * * \mathrm{P}<0.001$

Table 11. Phenotypic correlations of RFI with initial measures of body composition.

\begin{tabular}{|c|c|c|c|c|c|c|}
\hline Trait $^{1}$ & RFI & RIF & RUF & IMF & LMA & LMACWT \\
\hline RFI & 1.00 & $0.19^{*}$ & $0.17^{*}$ & -0.06 & 0.11 & $0.15^{\dagger}$ \\
\hline RIF & & 1.00 & $0.73^{* * *}$ & 0.08 & $0.53^{* * *}$ & $0.22^{* *}$ \\
\hline RUF & & & 1.00 & $0.15^{\dagger}$ & $0.48^{* * *}$ & $0.18^{*}$ \\
\hline IMF & & & & 1.00 & $-0.15^{\dagger}$ & $-0.19^{*}$ \\
\hline LMA & & & & & 1.00 & $0.79 * * *$ \\
\hline LMACWT & & & & & & 1.00 \\
\hline
\end{tabular}

${ }^{1} \mathrm{RFI}=$ residual feed intake; RIF $=$ ultrasound $12^{\text {th }}$ rib back fat; RUF $=$ ultrasound rump fat; IMF $=\%$ intramuscular fat; LMA $=12^{\text {th }}$ rib longissimus muscle area; LMACWT $=12^{\text {th }}$ rib longissimus muscle area per $100 \mathrm{~kg}$ body weight.

$\dagger \mathrm{P}<0.10, * \mathrm{P}<0.05, * * \mathrm{P}<0.01$, and $* * * \mathrm{P}<0.001$ 
Table 12. Phenotypic correlations of RFI with final measures of body composition.

\begin{tabular}{|c|c|c|c|c|c|l|}
\hline Trait $^{1}$ & RFI & RIF & RUF & IMF & LMA & LMACWT \\
\hline RFI & 1.00 & $0.27^{* *}$ & $0.24^{* *}$ & 0.03 & 0.12 & 0.13 \\
\hline RIF & & 1.00 & $0.78^{* * *}$ & $0.26^{* *}$ & $0.31^{* * *}$ & 0.00 \\
\hline RUF & & & 1.00 & $0.29^{* * *}$ & $0.33^{* * *}$ & 0.05 \\
\hline IMF & & & & 1.00 & $0.31^{* * *}$ & $0.20^{*}$ \\
\hline LMA & & & & & 1.00 & $0.81^{* * *}$ \\
\hline LMACWT & & & & & & 1.00 \\
\hline
\end{tabular}

${ }^{1}$ RFI = residual feed intake; RIF = ultrasound $12^{\text {th }}$ rib back fat; RUF = ultrasound rump fat; $\mathrm{IMF}=\%$ intramuscular fat; $\mathrm{LMA}=12^{\text {th }}$ rib longissimus muscle area; LMACWT = $12^{\text {th }}$ rib longissimus muscle area per $100 \mathrm{~kg}$ body weight.

$\dagger \mathrm{P}<0.10, * \mathrm{P}<0.05, * * \mathrm{P}<0.01$, and $* * * \mathrm{P}<0.001$ 
Table 13. Phenotypic correlations of RFI with change in (final - initial) body composition.

\begin{tabular}{|c|l|l|l|l|l|l|}
\hline Trait & RFI & $\Delta \mathrm{RIF}$ & $\Delta \mathrm{RUF}$ & $\Delta \mathrm{IMF}$ & $\Delta \mathrm{LMA}$ & $\Delta \mathrm{LMACWT}$ \\
\hline $\mathrm{RFI}$ & 1.00 & $0.18^{*}$ & 0.13 & 0.09 & 0.01 & -0.02 \\
\hline$\Delta \mathrm{RIF}$ & & 1.00 & $0.63^{* * *}$ & 0.04 & $0.28^{* *}$ & $0.25^{* *}$ \\
\hline$\Delta \mathrm{RUF}$ & & & 1.00 & 0.11 & $0.34^{* * *}$ & $0.31^{* * *}$ \\
\hline$\Delta \mathrm{IMF}$ & & & & 1.00 & 0.11 & 0.06 \\
\hline$\Delta \mathrm{LMA}$ & & & & & 1.00 & $0.96^{* * *}$ \\
\hline$\Delta \mathrm{LMACWT}$ & & & & & & 1.00 \\
\hline
\end{tabular}

${ }^{1} \mathrm{RFI}=$ residual feed intake; $\Delta \mathrm{RIF}=$ ultrasound $12^{\text {th }}$ rib back fat; $\Delta \mathrm{RUF}=$ ultrasound rump fat; $\Delta \mathrm{IMF}=\%$ intramuscular fat; $\Delta \mathrm{LMA}=12^{\text {th }}$ rib longissimus muscle area; $\Delta \mathrm{LMACWT}$ $=12^{\text {th }}$ rib longissimus muscle area per $100 \mathrm{~kg}$ body weight.

$\dagger \mathrm{P}<0.10, * \mathrm{P}<0.05, * * \mathrm{P}<0.01$, and $* * * \mathrm{P}<0.001$ 


\section{Age at Puberty}

Following is a table of summary statistics for the year-by-farm combinations:

Table 14. Summary statistics for AP.

\begin{tabular}{|c|c|c|c|c|c|c|}
\hline Farm & Year & $\mathrm{N}$ & Mean & SD & Minimum & Maximum \\
\hline \multirow{2}{*}{1} & 1 & 19 & 420.9 & 44.21 & 351 & 473 \\
\cline { 2 - 7 } & 2 & 22 & 457.5 & 22.50 & 411 & 497 \\
\hline \multirow{2}{*}{2} & 1 & 34 & 374.6 & 39.14 & 331 & 452 \\
\cline { 2 - 7 } & 2 & 21 & 446.3 & 18.80 & 405 & 477 \\
\hline \multirow{2}{*}{3} & 1 & 14 & 368.8 & 39.13 & 312 & 437 \\
\cline { 2 - 7 } & 2 & 27 & 453.4 & 20.22 & 411 & 489 \\
\hline
\end{tabular}

The previous table shows mild evidence of non-constant heifer variability

between years. Fitting a heterogeneous variance model to the AP data, with separate random cow effects variance components for each year, showed there was no practical effect on the inferences generated from this study. There was no evidence of any interaction effects involving RFI and fixed effects lending credence to the common slope ANCOVA linear mixed model used (F-tests not shown). Results for the F-tests for fixed effects are presented in Table 15.

Table 15. Type 3 tests of fixed effects.

\begin{tabular}{|c|c|c|c|c|}
\hline Effect & Num DF & Den DF & F Value & $\operatorname{Pr}>$ F \\
\hline Year & 1 & 130 & 121.61 & $<0.001$ \\
\hline Farm & 2 & 130 & 12.84 & $<0.001$ \\
\hline Year*Farm & 2 & 130 & 7.34 & 0.0010 \\
\hline RFI & 1 & 130 & 6.73 & 0.0106 \\
\hline
\end{tabular}


From this table, it is clear that a year by farm interaction significantly affects AP. Also, evidence of a negative linear association between AP and RFI was observed. An estimate of the change in AP with a one unit increase in RFI was -7.54 days (95\% confidence interval: $(-13.28,-1.79))$, or that age at puberty was reduced an average of 7.54 days for every one unit increase in RFI. Heifer variance was estimated to be 978.76 (95\% confidence interval: $(778.27,1268.54)$ ) while $\sigma^{2}$ was estimated to be 0.9990 . The $\mathrm{R}^{2}$ value for the fitted model was approximately 0.60 .

Using estimates of the fixed effects, a scatterplot displaying both the AP values and the fitted regression line for each year-by-farm combination is presented as Figure 5.

Figure 5. Fitted regression lines for Year-by-Farm combination.

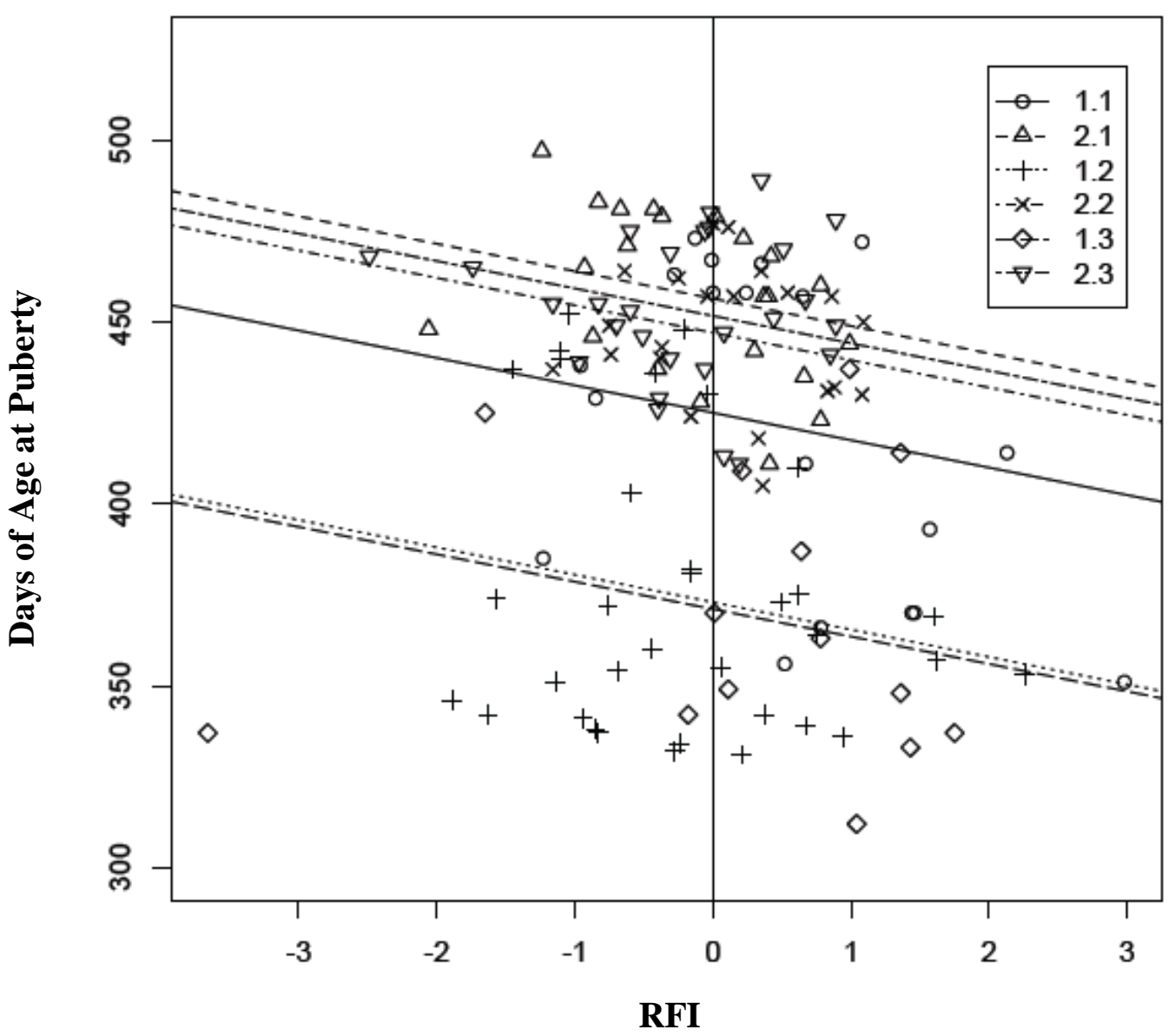

First Number in Legend in Year, Second is Farm 


\section{DISCUSSION}

\section{Growth and Body Composition}

Heifer growth performance $(1.14 \pm 0.21 \mathrm{~kg} / \mathrm{d})$ was similar to studies in which heifers were developed on a forage based ration. Lancaster et al. (2009b) reported mean ADG of Brangus heifers to be $1.01 \pm 0.15 \mathrm{~kg} / \mathrm{d}$ over four separate trials, while Lancaster et al. (2008) reported ADG to range from 0.88 to $1.05 \mathrm{~kg} / \mathrm{d}$ in Angus heifers. Quite unexpectedly, ADG was greater in MEDIUM heifers (1.17 vs. 1.10 and 1.09 kg/d, respectively, $\mathrm{P}<0.05$ ) when compared to both HIGH and LOW heifers. No other such reports are available in the literature, and it is unclear as to why this difference occurred. Residual Feed Intake was not phenotypically related $(r=0.00, P>0.10)$ to ADG and by definition RFI is independent of its component traits.

Although BW and Frame Score did not differ with RFI classification, measures of body composition, particularly subcutaneous fat stores, did. Phenotypic correlations with end of test RIF and gain in RIF were 0.27 and 0.18 , respectively. Similar to published reports (Arthur et al., 2001b; Basarab et al., 2003; Schenkel et al., 2004; Channon et al., 2004; Robinson and Oddy, 2004; Nkrumah et al., 2007c; Lancaster et al., 2009a;

Lancaster et al., 2009b; Kelly et al., 2010), higher RFI was associated with greater rib and rump fat measures. Muscle expression was not different except when expressed as a ratio with BW. Longissimus muscle area per hundred weight was greater in POS than NEG heifers (14.31 vs $13.56 \mathrm{~cm}^{2} / 100 \mathrm{~kg} \mathrm{BW,} \mathrm{P<0.01)} \mathrm{as} \mathrm{well} \mathrm{as} \mathrm{being} \mathrm{greater} \mathrm{in} \mathrm{HIGH} \mathrm{and}$ MEDIUM heifers when compared to LOW heifers (14.26 and 14.26 vs $13.41 \mathrm{~cm}^{2} / 100 \mathrm{~kg}$ BW, respectively). Indirect evidence for greater muscle expression in high RFI animals 
has been reported in Angus bulls (Lancaster et al., 2009a); however, greater error is associated with ratio traits (Gunsett, 1984), and observed differences in LMACWT may be an artifact of that error. It is generally apparent from the literature that ultrasound muscle expression does not differ based upon RFI classification. Nonetheless, the data provide evidence of a relationship between phenotypic RFI and body composition and further support the notion that measures of body composition, particularly subcutaneous fat measures, should be included in the calculation of RFI data to force independence and eliminate indirect selection effects.

\section{Age at Puberty}

Based upon RFI's independence of most other production traits, it was hypothesized that RFI should be independent of Age at Puberty; however, Age at Puberty differed between RFI classifications. In general, higher RFI heifers reached puberty at an earlier age than lower RFI heifers. Additionally, a linear association between RFI and Age at Puberty was observed indicating a one unit increase in RFI would result in the reduction of Age at Puberty an average of 7.54 days. Indirect evidence of this association has previously been reported (Arthur et al., 2005; Basarab et al., 2007), but there are no data in the literature to which a direct comparison can be made. Nonetheless, indirect comparison between RFI and traits known to affect Age at Puberty can be evaluated.

Age at Puberty in heifers is known to be negatively related to scrotal circumference in bulls (Smith et al., 1989; Martinez-Valazquez et al., 2003); however, scrotal circumference of Angus bulls was not related phenotypically or genetically to RFI in two separate studies (Arthur et al., 2001b; Schenkel et al., 2004). As the last physiological mechanism to activate, reproductive function is also related to maturity, 
which is strongly related to an increase in body fatness of livestock species. Knowing RFI's relationship to measures of fatness, it is possible that less efficient animals mature earlier and thus begin reproductive function at an earlier age. However, in this and other studies, there were no differences in indicators of mature size (hip height or frame score) between RFI groups. Considering the large discrepancy in feed intake between RFI groups, it is possible that less efficient animals stored excess consumed energy as fat, effectively "tricking” the physiological system into perceiving maturity and initiating reproductive function at an earlier age.

Attempting to explain the potential causes of the relationship between RFI and Age at Puberty in this manner is, however, incorrect. The negative linear association reported between RFI and Age at Puberty was determined using 'heifer' in the statistical model. Therefore, all sources of variation among heifers (ie. fatness, feed intake, sire, etc.) were accounted for. Nonetheless, without a greater understanding of the physiological mechanisms responsible for variation in RFI, it is unlikely that the factors responsible for differences in Age at Puberty with respect to RFI will be fully understood as they are likely to be, in part, interconnected. 


\section{CONCLUSION}

Residual feed intake in yearling beef heifers is positively related to subcutaneous fat measures. Addition of one or more of these measures into the calculation of RFI is warranted as it would force independence from these traits and eliminate indirect and potentially undesirable selection effects. As well, the data indicate selection for lesser RFI values may result in an increase in the age at puberty of females, which could result in reduced reproductive performance and productivity of breeding females. Within this population, it is unlikely that any potential negative effects on profit potential would be significant due to the reduction in feed costs of efficient females. Any potentially significant negative economical impact would most likely occur only after several generations of direct selection for reduction in RFI; however, the ability of this relationship to negatively impact cow/calf production systems long term is significant and warrants further investigation. 


\section{LITERATURE CITED}

Archer, J. A., Arthur, P.F., Herd, R. M., Parnell, P.F. and Pitchford, W.S., 1997.

Optimum postweaning test for measurement of growth rate, feed intake, and feed efficiency in British breed cattle. J. Anim. Sci. 75, 2024-2032.

Archer, J. A., E. C. Richardson, R. M. Herd and P. F. Arthur. 1999. Potential for selection to improve feed efficiency in British-bred cattle: A review. Aust. J. of Agric. Res. 50:147-161.

Archer, J. A., and L. Bergh. 2000. Duration of performance tests for growth rate, feed intake and feed efficiency in four biological types of beef cattle. Livest. Prod. Sci. 65:47-55.

Arije, G. F., and J. N. Wiltbank. 1971. Age and weight at puberty in Hereford heifers. J. Anim. Sci. 33:401-406.

Arije, G. F., and J. N. Wiltbank. 1974. Prediction of age and weight at puberty in beef heifers. J. Anim. Sci. 38:803.

Armsby, H. P., and J. A. Fries. 1911. The Influence of Type and of Age upon the Utilization of Feed by Cattle. Bull. No. 128. Washington, D. C.: U. S. Department of Agriculture, Bureau of Animal Industry.

Arthur, P. F., G. Renand and D. Krauss. 2001a. Genetic and phenotypic relationships among different measures of growth and feed efficiency in young Charolais bulls. Livest. Prod. Sci. 68:131-139.

Arthur, P. F., J. A. Archer, D. J. Johnston, R. M. Herd, E. C. Richardson and P. F. Parnell. 2001b. Genetic and phenotypic variance and covariance components for feed intake, feed efficiency and other postweaning traits in Angus cattle. J. Anim. Sci. 79:2805-2811.

Arthur, P. F., J. A. Archer, A. Reverter, D. J. Johnston and R. M. Herd. 2004. Genetic correlations between postweaning feed efficiency and cow traits. J. Anim. Sci. 82(Suppl. 1):449.

Arthur, P. F., R. M. Herd, J. F. Wilkins and J. A. Archer. 2005. Maternal productivity of Angus cows divergently selected for post-weaning residual feed intake. Aust. J. of Exp. Agr. 45:985-993.

Basarab, J. A., M. A. Price, J. L. Aalhus, E. K. Okine, W. M. Snelling and K. L. Lyle. 2003. Residual feed intake and body composition in young growing cattle. Can. J. Anim. Sci. 83:189-204. 
Basarab, J. A., D. McCartney, E. K. Okine and V. S. Baron. 2007. Relationships between progeny residual feed intake and dam productivity traits. Can. J. Anim. Sci. 87:489-502.

Berardinelli, J. G. 1976. Induction of puberty in beef heifers. Masters Thesis. West Virginia University.

Berardinelli, J. G., and P. S. Joshi. 2005a. Introduction of bulls at different days postpartum on resumption of ovarian cycling activity in primiparous beef cows. J. Anim. Sci. 83:2106-2110.

Berardinelli, J. G., and P. S. Joshi. 2005b. Initiation of postpartum luteal function in primiparous restricted-suckled beef cows exposed to a bull or excretory products of bulls or cows. J. Anim. Sci. 83:2495-2500.

Berardinelli, J. G., P. S. Joshi and S. A. Tauck. 2007. Conception rates to artificial insemination in primiparous, suckled cows exposed to the biostimulatory effect of bull before and during a gonadotropin-releasing hormone-based estrus synchronization protocol. J. Anim. Sci. 85:848-852.

Bingham, G. M., T .H. Friend, P. A. Lancaster and G. E. Carstens. 2009. Relationship between feeding behavior and residual feed intake in growing Brangus heifers. J. Anim. Sci. 87:2685-2689.

Blaxter, K. L., and A. W. Boyne. 1982. Fasting and maintenance metabolism of sheep. J. Agric. Sci. Camb. 99:611-620.

Blaxter, K. L., and F. W. Wainman. 1966. The fasting metabolism of cattle. Br. J. Nutr. 20:103-111.

Bottje, W. G., and G. E. Carstens. 2009. Association of mitochondrial function and feed efficiency in poultry and livestock species. J. Anim. Sci. 87(E. Suppl.):E48-E63.

Brody, S. 1945. Bioenergetics and Growth. New York: Hafner.

Buskirk, D. D., D. B. Faulkner and F. A. Ireland. 1995. Increased postweaning gain of beef heifers enhances fertility and milk production. J. Anim. Sci. 73:937-946.

Byerley, D. J., R. B. Staigmiller, J. G. Berardinelli and R. E. Short. 1987. Pregnancy rates of beef heifers bred either on puberal or third estrus. J. Anim. Sci. 65:645.

Castro Bulle, F. C. P., P. V. Paulino, A. C. Sanches and R. D. Sainz. 2007. Growth, carcass quality, and protein and energy metabolism in beef cattle with different growth potentials and residual feed intakes. J. Anim. Sci. 85:928-936. 
Channon, A. F., J. B. Rowe and R. M. Herd. 2004. Genetic Variation in starch digestion in feedlot cattle and its association with residual feed intake. Aust. J. of Exp. Agr. 44:469-474.

Christopherson, R. J., R. J. Hudson and M. K. Christopherson. 1979. Seasonal energy expenditures and thermoregulatory response of bison and cattle. Can. J. Anim. Sci. 59:611-617.

Clanton, D. C., L. E. Jones and M. E. England. 1983. Effect of rate and time of gain after weaning on the development of replacement beef heifers. J. Anim. Sci. 56:280285.

Crews, D. H. Jr., 2005. Genetics of efficient feed utilization and national cattle evaluation: a review. Genet. Mol. Res. 4:152-165.

Cruz, G. D., J. A. Rodriguez-Sanchez, J. W. Oltjen and R. D. Sainz. 2010. Performance, residual feed intake, digestibility, carcass traits, and profitability of AngusHereford steers housed in individual or group pens. J. Anim. Sci. 88:324-329.

Dow, J. S., Jr., J. D. Moore, C. M. Bailey and W. D. Foote. 1982. Onset of puberty in heifers of diverse beef breeds and crosses. J. Anim. Sci. 55:1041-1047.

Elzo, M. A., D. G. Riley, G. R. Hansen, D. D. Johnson, R. O. Meyer, S. W. Coleman, C. C. Chase, J. G. Wasdin and J. D. Driver. Effect of breed composition on phenotypic residual feed intake and growth in Angus, Brahman, and Angus X Brahman crossbred cattle. J. Anim. Sci. 87:3877-3886.

Ferrell, C. L. 1982. Effects of postweaning rate of gain on onset of puberty and productive performance of heifers of different breeds. J. Anim. Sci. 55:12721283.

Ferrell, C. L., and T. G. Jenkins. 1984. Energy utilization by mature, nonpregnant, nonlactating cows of different breeds. J. Anim. Sci. 58:234-243.

Ferrell, C. L., and T. G. Jenkins. 1985a. Energy utilization by Hereford and Simmental males and females. Anim. Prod. 41:53-61.

Ferrell, C. L., and T. G. Jenkins. 1985b. Cow type and the nutritional environment: Nutritional aspects. J. Anim. Sci. 61:725-741.

Ferrell, C. L., W. N. Garrett, N. Hinman and G. Grichting. 1976. Energy utilization by pregnant and nonpregnant heifers. J. Anim. Sci. 42:790-801.

Ferrell, C. L., J. D. Crouse, R. A. Field and J. L. Chant. 1979. Effects of sex, diet and stage of growth upon energy utilization by lambs. J. Anim. Sci. 49:790-801. 
Fitzhugh, H. A., Jr., and C. S. St. Taylor. 1971. Genetic analysis of degree of maturity. J. Anim. Sci. 33:717-725.

Garrett, W. N. 1971. Energetic efficiency of beef and dairy steers. J. Anim. Sci. 32:451456.

Gaskins, C. T., R. L. Preston and J. R. Males. 1982. Feed requirements for maintenance and gain in crossbred bulls of two types. J. Anim. Sci. 55:67-72.

Goonewardene, L. A., E. Okine, Z. Wang, D. Spaner, P. S. Mir, Z. Mir and T. Marx. 2004. Residual metabolizable energy intake and its association with test duration. Can. J. Anim. Sci. 84:291-295.

Graham, N. McC. 1964. Energy exchanges of pregnant and lactating ewes. Aust. J. of Agr. Res. 15:127.

Gregory, K. E. 1972. Beef cattle type for maximum efficiency 'Putting it all together'. J. Anim. Sci. 34:881-884.

Gunsett, F. C. 1984. Linear index selection to improve traits defined as ratios. J. Anim. Sci. 63:111-119.

Herd, R. M., E. C. Richardson, R. S. Hegarty, R. Woodgate, J. A. Archer and P. F. Arthur. 1998. Pasture intake by high versus low net feed efficient Angus cows. Anim. Prod. In Aust. 22:137-140.

Herd, R. M., and S. C. Bishop. 2000. Genetic variation in residual feed intake and its association with other production traits in British Hereford cattle. Livest. Prod. 59:1185-1193.

Herd, R. M., and P. F. Arthur. 2009. Physiological basis for residual feed intake. J. Anim. Sci. 87:E64-E71.

Hoque, M. A., M. Hosono, T. Oikawa and K. Suzuki. 2009. Genetic parameters for measures of energetic efficiency of bulls and their relationships with carcass traits of field progeny in Japanese Black cattle. J. Anim. Sci. 87:99-106.

Hotovy, S. K., K. A. Johnson, D. E. Johnson, G. E. Carstens, R. M. Bourdon and G. E., Jr Seidel. 1991. Variation among twin beef cattle in maintenance energy requirements. J. Anim. Sci. 69: 940-946.

Hutcheson, J. P., D. E. Johnson, C. L. Gerken, J. B. Morgan and J. D. Tatum. 1997. Anabolic implant effects on visceral organ mass, chemical body composition, and estimated energetic efficiency in cloned (genetically identical) beef steers. J. Anim. Sci. 75: 2620-2626. 
Jenkins, T. G., and C. L. Ferrell. 1983. Nutrient requirements to maintain weight of mature, nonlactating, nonpregnant cows of four diverse breed types. J. Anim. Sci. 56:761-770.

Jensen, J., I. L. Mao, B. B. Andersen and P. Madsen. 1992. Phenotypic and genetic relationships between residual energy intake and growth, feed intake, and carcass traits of young bulls. J. Anim. Sci. 70:386-395.

Joubert, D. M. 1963. Puberty in female farm animals. An. Breed. Abstr. 31:295.

Kearney, G. A., B. W. Knee, J. F. Graham and S. A. Knott. 2004. The length of test required to measure liveweight change when testing for feed efficiency in cattle. Australian J. Exp. Agr. 44:411-414.

Kellner, O. 1909. The Scientific Feeding of Animals. McMillan Company, New York.

Kelly, A. K., M. McGee, D. H. Crews Jr., A. G. Fahey, A. R. Wylie and D. A. Kenny. 2010. Effect of divergence in residual feed intake on feeding behavior, blood metabolic variables, and body composition traits in growing beef heifers. J. Anim. Sci. 88:109-123.

Klieber, M. 1947. Body Size and metabolic rate. Physiol. Rev. 27:511-541.

Klosterman, E. W., L. G. Sanford and C. F. Parker. 1968. Effects of cow size and condition and ration protein content upon maintenance requirements of mature beef cows. J. Anim. Sci. 27:242.

Koch, R. M., L. A. Swiger, D. Chambers and K. E. Gregory. 1963. Efficiency of feed use in cattle. J. Anim. Sci. 22:486-494.

Kolath, W. H., M. S. Kerley, J. W. Golden and D. H. Keisler. 2006a. The relationship between mitochondrial function and residual feed intake in Angus steers. J. Anim. Sci. 84:861-865.

Kolath, W. H., M. S. Kerley, J. W. Golden, S. A. Shahid and G. S. Johnson. 2006b. The relationships among mitochondrial uncoupling protein 2 and 3 expression, mitochondrial deoxyribonucleic acid single nucleotide polymorphisms, and residual feed intake in Angus steers. J. Anim. Sci. 84:1761-1766.

Koots, K. R., and J. P. Gibson. 1998. Economic values for beef production traits from a herd level bioeconomic model. Can. J. Anim. Sci. 78:29-45.

Lancaster, P. A., G. E. Carstens, F. R. B. Ribeiro, M. E. Davis, J. G. Lyons and T. H. Welsh, Jr. 2008. Effects of divergent selection for serum insulin-like growth factor-I concentration on performance, feed efficiency, and ultrasound measures 
of carcass composition traits in Angus bulls and heifers. J. Anim. Sci. 86:28622871.

Lancaster, P. A., G. E. Carstens, F. R. B. Ribeiro, L. O. Tedeschi and D. H. Crews, Jr. 2009a. Characterization of feed efficiency traits and relationships with feeding behavior and ultrasound carcass characteristics in growing bulls. J. Anim. Sci. 87:1528-1539.

Lancaster, P. A., G. E. Carstens, D. H. Crews Jr., T. H. Welsh Jr., T. D. A. Forbes, D. W. Forrest, L. O. Tedeschi, R. D. Randel and F. M. Rouquette. 2009b. Phenotypic and genetic relationships of residual feed intake with performance and ultrasound carcass characteristics of Brangus heifers. J. Anim. Sci. 87:3887-3896.

Laster, D. B., H. A. Glimp and K. E. Gregory. 1972. Age and weight at puberty and conception in different breeds and breed-crosses of beef heifers. J. Anim. Sci. 34:1031-1036.

Laurenz, J. C., F. M. Byers, G. T. Schelling and L. W. Green. 1991. Effects of seasonal environment on the maintenance requirement of mature beef cows. J. Anim. Sci. 69:2168-2176.

Lemenager, R. P., L. A. Nelson and K. S. Hendrix. 1980. Influence of cow size and breed type on energy requirements. J. Anim. Sci. 51:566-576.

Lesmeister, J. L., P. J. Burfening and R. L. Blackwell. 1973. Date of first calving in beef cows and subsequent calf production. J. Anim. Sci. 36:1-6.

Lynch, J. M., G. C. Lamb, B. L. Miller, R. T. Brandt, Jr., R. C. Cochran and J. E. Minton. 1997. Influence of timing of gain on growth and reproductive performance of beef replacement heifers. J. Anim. Sci. 75:1715-1722.

Liu, M. F., L. A. Goondwardene, D. R. C. Bailey, J. A. Basarab, R. A. Kemp, P. F. Arthure, E. K. Okine and M. Makarechian. 2000. A study on the variation of feed efficiency in station tested beef bulls. Can. J. Anim. Sci. 80: 435-441.

Lofgreen, G. P. and W. N. Garrett. 1968. A system for expressing net energy requirements and feed values for growing and finishing cattle. J. Anim. Sci. 27:793-806.

Mader, C. J., Y. R. Montanholi, Y. J. Wang, S. P. Miller, I. B. Mandell, B. W. McBride and K. C. Swanson. 2009. Relationships among measures of growth performance and efficiency with carcass traits, visceral organ mass, and pancreatic digestive enzymes in feedlot cattle. J. Anim. Sci. 87:1548-1557. 
Martinez-Valazquez, G., K. E. Gregory, G. L. Bennett and L. D. Van Vleck. 2003. Genetic relationships between scrotal circumference and female reproductive traits. J. Anim. Sci. 81:395-401.

Meyer, A. M., M. S. Kerley and R. L. Kallenbach. 2008. The effect of residual feed intake classification on forage intake by grazing beef cows. J. Anim. Sci. 86:2670-2679.

Milliken, G. A., and Johnson, D. E. 2002. Analysis of Messy Data, Volume III: Analysis of Covariance. Chapman and Hall/CRC, Boca Raton, FL.

Moe, P. W., and H. F. Tyrell. 1972. Metabolizable energy requirements of pregnant dairy cows. J. Dairy Sci. 55:480-483.

Montano-Bermudez, M., M. K. Neilsen and G. Deutscher. 1990. Energy requirements for maintenance of crossbred beef cattle with different genetic potential for milk. J. Anim. Sci. 68:2279-2288.

National Research Council. 1996. Nutrient Requirements of Beef Cattle, Sixth Rev. Ed. Washington, D.C.: National Academy Press.

Neufeldt, Victoria. 1997. Webster's New World College Dictionary. New York. Simon and Schuster Macmillan Company.

Neville, W. E., Jr. 1974. Comparison of energy requirements of nonlactating and lactating Hereford cows and estimates of energetic efficiency of milk production. J. Anim. Sci. 38:681-686.

Neville, W. E., Jr., and M. E. McCullough. 1969. Calculated net energy requirements of lactating and nonlactating Hereford cows. J. Anim. Sci. 29:823-829.

Nkrumah, J. D., J. A. Basarab, M. A. Price, E. K. Okine, A. Ammoura, S. Guercio, C. Hansen, C. Li, B. Benkel, B. Murdoch and S. S. Moore. 2004. Different measures of energetic efficiency and their phenotypic relationships with growth, feed intake, and ultrasound and carcass merit in hybrid cattle. J. Anim. Sci. 82:24512459.

Nkrumah, J. D., E. K. Okine, G. W. Mathison, K. Schmid, C. Li, J. A. Basarab, M. A. Price, Z. Wang and S. S. Moore. 2006. Relationships of feedlot feed efficiency, performance, and feeding behavior with metabolic rate, methane production, and energy partitioning in beef cattle. J. Anim. Sci. 84:145-153.

Nkrumah, J. D., D. H. Keisler, D. H. Crews, Jr., J. A. Basarab, Z. Wang, C. Li, M. A. Price, E. K. Okine and S. S. Moore. 2007a. Genetic and phenotypic relationships of serum leptin concentration with performance, efficiency of gain, and carcass merit of feedlot cattle. J. Anim. Sci. 85:2147-2155. 
Nkrumah, J. D., D. H. Crews Jr., J. A. Basarab, M. A. Price, E. K. Okine, Z. Wang, C. Li and S. S. Moore. 2007b. Genetic and phenotypic relationships of feeding behavior and temperament with performance, feed efficiency, ultrasound, and carcass merit of beef cattle. J. Anim. Sci. 85:2382-2390.

Nkrumah, J. D., J. A. Basarab, Z. Wang, C. Li, M. A. Price, E. K. Okine, D. H. Crews Jr. and S. S. Moore. 2007c. Genetic and phenotypic relationships of feed intake and different measures of feed efficiency with growth and carcass merit of beef cattle. J. Anim. Sci. 85:2711-2720.

Old, C. A., and W. N. Garrett. 1987. Effects of energy intake on energetic efficiency and body composition of beef steers differing in size at maturity. J. Anim. Sci. 65:1371-1380.

Patle, B. R., and V. D. Mudgal. 1977. Utilization of dietary energy requirements for maintenance, milk production and lipogenesis by lactating crossbred cows during their midstage of lactation. Br. J. Nutr. 37:23-33.

Patterson, D. J., R. C. Perry, G. H. Kiracofe, R. A. Bellows, R. B. Staigmiller and L. R. Corah. 1992. Management considerations in heifer development and puberty. J. Anim. Sci. 70:4018-4035.

Rattray, P. V., W. N. Garrett, N. E. East and N. Hinman. 1974. Efficiency of utilization of metabolizable energy during pregnancy and the energy requirements of pregnancy in sheep. J. Anim. Sci. 38:383.

Reynolds, W. L., T. M. DeRouen and J. W. High, Jr. 1963. The age and weight at puberty of Angus, Brahman, and Zebu cross heifers. J. Anim. Sci. 22:243 (abstr.).

Richardson, E. C., R. M. Herd, V. H. Oddy, J. M. Thompson, J. A. Archer and P. F. Arthur. 2001. Body composition and implications for heat production of Angus steer progeny of parents selected for and against residual feed intake. Aust. J. of Exp. Agr. 41:1065-1072.

Richardson, E. C., R. M. Herd, I. G. Colditz, J. A. Archer and P. F. Arthur. 2002. Blood cell profiles of steer progeny from parents selected for and against residual feed intake. Aust. J. of Exp. Agr. 42:901-908.

Richardson, E. C., and R. M. Herd. 2004. Biological basis for variation in residual feed intake in beef cattle. 2. Synthesis of results following divergent selection. Aust. J. of Exp. Agr. 44:41-440.

Robinson, D. L., and V. H. Oddy. 2004. Genetic parameters for feed efficiency, fatness, muscle area and feeding behaviour of feedlot finished beef cattle. Livest. Prod. Sci. 90:255-270. 
Rumsey, T. S., H. F. Tyrrell and P. W. Moe. 1980. Effect of diethylstilbestrol and Synovex-S on fasting metabolism measurements of beef steers. J. Anim. Sci. 50:160-166.

Schenkel, F. S., S. P. Miller and J. W. Wilton. 2004. Genetic parameters and breed differences for feed efficiency, growth, and body composition traits of young beef bulls. Can. J. Anim. Sci. 84:177-185.

Schillo, K. K., D. J. Dierschke and E. R. Hauser. 1982. Influences of month of birth and age on patterns of luteinizing hormone secretion in prepubertal heifers. Theriogenology. 18:593-598.

Schillo, K. K., J. B. Hall and S. M. Hileman. 1992. Effects of nutrition and season on the onset of puberty in the beef heifer. J. Anim. Sci. 67:2994-4005.

Short, R. E., and R. A. Bellows. 1971. Relationships amoung weight gains, age at puberty and reproductive performance in heifers. J. Anim. Sci. 32:127-131.

Smith, B. A., J. S. Brinks and G. V. Richardson. 1989. Relationship of sire scrotal circumference to offspring reproduction and growth. J. Anim. Sci. 67:2881-2885.

Solis, J. C., F. M. Byers, G. T. Schelling, C. R. Long and L. W. Green. 1988.

Maintenance requirements and energetic efficiency of cows of different breeds. J. Anim. Sci. 66:764-773.

Stick, D. A., M. E. Davis, S. C. Loerch and R. C. Simmen. 1998. Relationship between blood serum insulin-like growth factor I concentration and postweaning feed efficiency of crossbred cattle at three levels of dietary intake. J. Anim. Sci. 76:498-505.

Tauck, S. A., J. G. Berardinelli, T. W. Geary and N. J. Johnson. 2006. Resumption of postpartum luteal function of primiparous, suckled beef cows exposed continuously to bull urine. J. Anim. Sci. 84:2708-2713.

Tauck, S. A., and J. G. Berardinelli. 2007. Putative urinary pheromone of bulls involved with breeding performance of primiparous beef cows in a progestin-based estrous synchronization protocol. J. Anim. Sci. 85:1669-1674.

Tortonese, D. J., and E. K. Inskeep. 1992. Effects of melatonin treatment on the attainment of puberty in heifers. J. Anim. Sci. 70:2822-2827.

Turner, H. A., G. B. Thompson and J. L. Clark. 1974. Cow size as related to energetic efficiency. J. Anim. Sci. 39:256 (Abstr.).

Vonesh, E. F., and Chinchilli, V. M. 1997. Linear and Nonlinear Models for the Analysis of Repeated Measurements. Marcel Dekker, New York, NY. 
Wang, Z., J. A. Basarab, L. A. Goonewardene, D. H. Crews, Jr., P. Ramsey, K. L. Lyle, N. French, E. K. Okine and S. S. Moore. 2005. Test duration for residual feed intake in commercial bulls. J. Anim. Vet Adv. 4:825-830.

Wang, Z., J. D. Nkrumah, C. Li, J. A. Basarab, L. A. Goonewardene, E. K. Okine. D. H. Crews, Jr. and S. S. Moore. 2006. Test duration for growth, feed intake, and feed efficiency in beef cattle using the GrowSafe System. J. Anim. Sci. 84:2289-2298.

Wiltbank, J. N., K. E. Gregory, L. E. Swiger, J. E. Ingalls, J. A. Rothlisberger and R. M. Kock. 1966. Effects of heterosis on age and weight at puberty in beef heifers. J. Anim. Sci. 25:744-751.

Wiltbank, J. D., S. Roberts, J. Nix and L. Rowden. 1985. Reproductive performance and profitability of heifers fed to weigh 272 or $318 \mathrm{~kg}$ at the start of the first breeding season. J. Anim. Sci. 60:25-34.

“2009 Farm Production Expenditures Annual Summary” USDA-NASS, 2009.

“2004 Farm Production Expenditures Annual Summary” USDA-NASS, 2004. 


\section{VITA}

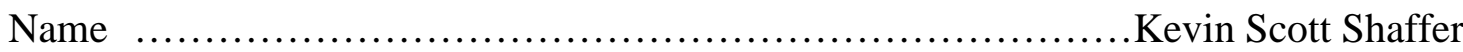

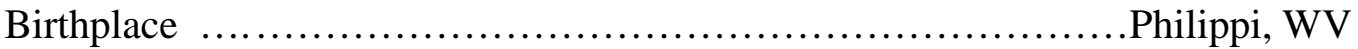

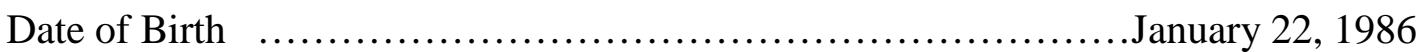

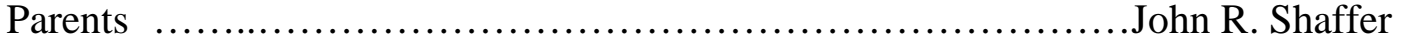
Nancy L. Shaffer

Schools Attended:

Philip Barbour High School .........................2000-2004

Philippi, WV

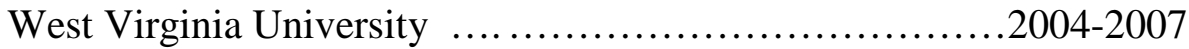
Morgantown, WV

Degrees Received:

Bachelor of Science in Animal and Veterinary Science

West Virginia University, 2007 


\section{RESIDUAL FEED INTAKE, BODY COMPOSITION AND FERTILITY IN YEARLING BEEF HEIFERS}

Kevin S. Shaffer

Thesis submitted to the

Davis College of Agriculture, Natural Resources, and Design

at West Virginia University

in partial fulfillment of the requirements

for the degree of

Master of Science

in

Animal and Nutritional Science

Department of Animal and Nutritional Science

APPROVAL OF THE EXAMINING COMMITTEE

Eugene E. D. Felton, Ph.D., Chair

E. Keith Inskeep, Ph.D.

Wayne R. Wagner, Ph.D.

Date

John E. Warren, Jr., Ph.D.

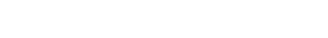

John H.

Hagen 